\title{
SISTEMA DE CLASSIFICAÇÃO DE PACIENTES: CONSTRUÇÃO E VALIDAÇÃODE UM INSTRUMENTO
}

\author{
Dissertação apresentada ao Programa de \\ Pós- Graduação, Nível Mestrado da Escola \\ de Enfermagem da Universidade de São \\ Paulo, para obtenção do título de Mestre
}

Candidata :

\section{Marcia Galan Perroca}

Orientadora :

Prof. Dra. Raquel Rapone Gaidzinski

São Paulo

1996 


\section{AGRADECIMENTOS}

À orientadora Prof ${ }^{a}$ Dra Raquel Rapone Gaidzinski pela condução paciente e carinhosa.

Às enfermeiras que atuaram como juizes pela valiosa contribuição compartilh ando suas experiências.

À amiga Dra Zaida Aurora Sperli Geraldes Soler pelo auxílio in estimável, substituindo-me em minhas au sências.

À Maria do Carmo Vita Ricci, coordenadora do Curso de Enfermagem da Faculdade de Medicina de São José do Rio Preto, pelo estímulo e por acreditar na potencialidade da enfermeira.

Ao psicólogo Nelson Iguimar Valério pela disponibilidade e apoio na construção do indicador Comportamento . Ao Dr Jair Licio Ferreira Santos pela análise estatística. À Sônia Maria Gardim pela revisão bibliográfica.

A todos aqueles que, de alguma forma, contribuiram para a realização deste estudo. 


\section{DEDICATÓRIA}

Aos meus pais,

\section{Reinaldo e Mercedes}

pelo extremado amor e dedicação

tornando-me pessoa

À tia Irene,

pelo carinho e dedicação 


\section{RESUMO}

Este estudo teve por finalidade a construção e validação de um instrumento para classificação de pacientes baseado nas necessidades individualizadas de cuidado de enfermagem. Para compor o instrumento foram considerados 13 indicadores críticos : Estado Mental e Nível de Consciência, Oxigenação, Sinais Vitais, Nutrição e Hidratação, Motilidade, Locomoção, Cuidado Corporal, Eliminações, Terapêutica, Educação à Saúde, Comportamento, Comunicação e Integridade Cutâneo-Mucosa. Cada um desses indicadores possui gradação de 1 a 5, apontando a intensidade crescente da complexidade assistencial. $\mathrm{O}$ paciente é classificado em todos os indicadores em um dos 5 níveis, na opção que melhor descreva a sua situação. Para validação do conteúdo foi aplicada a Técnica Delphi em 2 fases. Participaram como juízes 15 profissionais da área de enfermagem que atuam junto a instituições de assistência ou vinculados a Hospital Escola na cidade de São José do Rio Preto. Os resultados obtidos mostraram concordância dos juízes quanto a : manutenção dos 13 indicadores críticos no instrumento; pertinência e clareza do conteúdo dos indicadores críticos e a existência de nível de complexidade assistencial crescente. 


\begin{abstract}
This study had in its aim the construction and the validation of a patient classification instrument which has been based on the patient's individual necessities that require the nursing care. It was considered in the instrument 13 critical indicators : Mental State and Level of Conciousness, Breathing, Vital Signs, Nutrition and Hydration, Movement, Locomotion, Corporeal Hygiene, Eliminations, Therapy, Health Teaching, Behavior, Communication and Skin Integrety. Each one of these indicators has a 1 to 5 gradation denoting an increasing level in the nursing care complexity. The patient is classified in all the indicators in one of the five levels, in the option that better describes his/her situation. The content validation of the instrument was done by the Delphi Tecnique aplication through 2 rounds. A team of 15 nursing experts who attend pacients or teach in the Medical School in São José do Rio Preto were participants in this research. The obtained results have showed the experts' agreement concerned to: the maintenance of the 13 critical indicators in the instrument; property and intelligibility of the critical indicator contents and the presence of an increasing level in the nursing care complexity.
\end{abstract}




\section{SUMÁRIO}

Resumo

Abstract

1 INTRODUÇÃO

2 OBJETIVOS ------------------------------------------------------------------------------------- 14

3 MÉTODO ------------------------------------------------------------------------------------ 15

3.1 Construção do Instrumento de Classificação de Pacientes ------------------------- 15

3.2 Técnica de Validação do Instrumento de Classificação de Pacientes ------------ 17

3.3 Método para Padronização do Escore -------------------------------------------------- 23

4 CONSTRUINDO OS RESULTADOS ------ 26

4.1 Fase Delphi I ------------------------------------------------------------------------------ 33

4.1.1 Identificação dos Juízes ---------------------------------------------------------------- 33

4.1.2 Resultados -------------------------------------------------------------------------------- 35

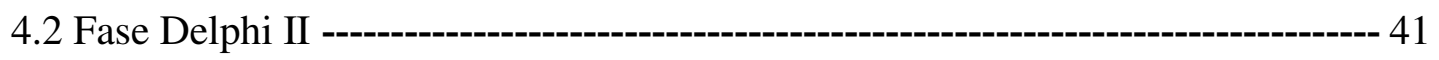

4.2.1 Resultados ---------------------------------------------------------------------------------- 41

4.3 Proposta Final do Instrumento para Classificação de Pacientes ------------------ 53

5 CONCLUSÕES -------------------------------------------------------------------------------- 64

\section{ANEXOS}

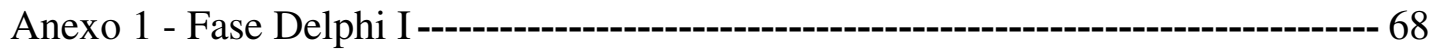

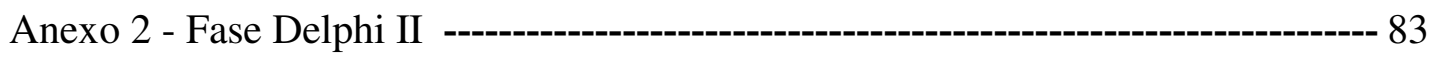

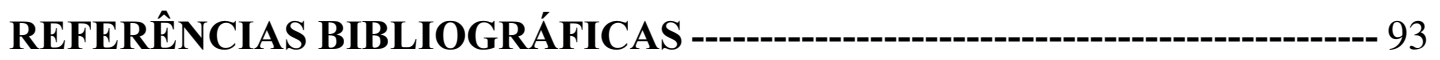




\section{INTRODUÇÃO}

O Sistema de Classificação de Pacientes (SCP) é um processo no qual se procura categorizar pacientes de acordo com a quantidade de cuidado de enfermagem requerido, ou seja, baseado na complexidade da assistência de enfermagem.

GIOVANNETTI (1979) conceitua SCP como "a identificação e classificação de pacientes em grupos de cuidados ou categorias, e a quantificação destas categorias como uma medida dos esforços de enfermagem requeridos". DE GROOT (1989a) amplia este conceito abordando o SCP como um método capaz de determinar, validar e monitorar as necessidades de cuidado individualizado do paciente, utilizando os dados obtidos como subsídio para alocação de pessoal de enfermagem, planejamento de custos da assistência e manutenção de padrões de qualidade.

O SCP vem sendo desenvolvido e aperfeiçoado nos Estados Unidos há cerca de 30 anos e, apesar de ainda trazer em si algumas limitações, constitui importante instrumento para prática administrativa de enfermagem norteando, principalmente, o processo decisório relacionado à alocação de recursos humanos.

Compete ao enfermeiro no desempenho de suas funções gerenciais coordenar o processo de provimento de pessoal de enfermagem. A forma pela qual o quadro de pessoal de enfermagem está organizado, quantitativamente e qualitativamente, reflete a filosofia do Serviço de Enfermagem na instituição, bem como o compromisso com a qualidade da assistência a ser prestada ao paciente. 
Exaustivos estudos destinados a calcular o pessoal de enfermagem têm sido desenvolvidos ao longo dos anos na tentativa de se estabelecer um método que se ajuste às reais necessidades dos diversos serviços. A contagem do número de leitos ocupados, proporcionalidade pessoal de enfermagem / paciente e hora média de assistência de enfermagem têm sido experimentados como parâmetros para o dimensionamento do pessoal de enfermagem. Contudo, estes métodos tradicionais têm se mostrado insatisfatórios por considerarem todos os pacientes como detentores do mesmo nível de atenção de enfermagem, não levando em conta a variação da gravidade dos pacientes e sua consequente influência na alocação de recursos humanos nas unidades (GAIDZINSKI, 1994).

Dimensionar recursos humanos para a assistência de enfermagem pode se tornar mais racional e efetivo quando se procura agrupar pacientes em categorias que reflitam a magnitude do processo de cuidar (GIOVANNETTI, 1979). O sistema de categorização de pacientes pode justificar, ainda, ao administrador hospitalar a necessidade de pessoal adicional quando ocorre aumento do volume de trabalho na unidade (ALWARD, 1983).

O SCP também tem sido utilizado para auxiliar o processo orçamentário do Serviço de Enfermagem (ALWARD, 1983; ARNDT; HUCKABAY, 1983; DIJKERS; PARADISE, 1986; DE GROOT, 1989A; VAN SLYCK, 1991; WRONA-SEXTON, 1992; RODRIGUES FILHO, 1992; PHILLIPS et al, 1992).

O custeio do cuidado de enfermagem representa parte significativa do total da receita hospitalar. Geralmente, todos os pacientes são tratados como se consumissem a mesma intensidade de cuidados de enfermagem, o que não é verdadeiro. O SCP, determinando os diferentes volumes de recursos necessários à 
assistência, permite a mensuração dos custos do cuidado de enfermagem para pacientes nos diferentes níveis de atenção bem como uma melhor avaliação da produtividade (MATOS, 1995).

De acordo com ALWARD (1983) o SCP ideal deveria :" 1- combinar necessidades do paciente com recursos de enfermagem; 2- projetar necessidades de pessoal para o orçamento de enfermagem; 3- medir a eficiência das enfermeiras gerenciais; 4- justificar mudanças temporárias e permanentes no quadro de pessoal; 5- proporcionar uma base para custos de enfermagem ".

Acrescenta, ainda, ALWARD (1983) que o enfermeiro, no gerenciamento do Serviço de Enfermagem, pode utilizar o SCP com o propósito de estabelecer programas para garantia de qualidade, através da obtenção de dados sobre a quantidade e a qualidade do cuidado proporcionado nas unidades, estabelecendo prioridades para melhoria da assistência .

A idéia de classificar pacientes não é recente. Florence Nightingale também se utilizou desta prática buscando localizar, mais convenientemente, na enfermaria, os pacientes cujo nível de cuidado demandava maior atenção de enfermagem (RIBEIRO, 1972 ; ALCALÁ et al, 1982).

Contudo, a classificação de pacientes de forma sistematizada parece ter iniciado com o conceito do Cuidado Progressivo ao Paciente (CPP). De acordo com ALVES et al (1988), o CPP pode ser conceituado como a "concentração variável de recursos humanos e materiais em torno das necessidades do cliente, visando uma assistência integral e humanizada".

Seis categorias compõem o CPP : cuidados intensivos, cuidados intermediários, cuidados prolongados para pacientes crônicos, auto-cuidado ou 
cuidados mínimos, cuidados ambulatoriais e cuidados domiciliares (RIBEIRO, 1972; OLIVEIRA;ROMÁN, 1976; ALCALÁ et al, 1982; ALVES et al , 1988).

Nos hospitais brasileiros a adoção do conceito do CPP não está claramente definida. No entanto, percebe-se a existência de áreas como Unidades de Tratamento Intensivo (UTI), Unidade de Cuidado Semi-Intensivo (UCSI) e Unidades de Internação como preconizadas pelas diretrizes da assistência progressiva (CAR, 1986).

Um estudo realizado na década de 30 nos hospitais de Nova York, segundo RODRIGUES FILHO (1992), é tido como precursor no desenvolvimento de sistemas de classificação, identificando as necessidades de cuidado dos pacientes e propondo horas de assistência de enfermagem.

Nos anos 50, o Exército dos Estados Unidos desenvolveu um método para classificar pacientes sugerindo um instrumento de avaliação a partir de indicadores críticos que denominou de protótipo (ALWARD, 1983).

Contudo, a liderança no estudo de classificação de pacientes, indubitavelmente, cabe a um grupo de pesquisadores formado no John Hopkins University and Hospital, nos Estados Unidos, em maio de 1961. Este grupo desenvolveu um sistema para classificação baseado no grau de necessidade do paciente em relação à assistência de enfermagem. Os pacientes foram classificados em 3 grupos: auto-cuidado, cuidado parcial ou intermediário e cuidado intensivo ou total e a média de horas de assistência de enfermagem por paciente foi determinada para cada classificação. Os pesquisadores concluíram o estudo afirmando que "técnicas para classificação de pacientes proporcionam um efetivo mecanismo 
administrativo para estimativas diárias de necessidades dos pacientes em relação à assistência de enfermagem e de recursos materiais" (CONNOR et al, 1961).

Em uma análise sobre as atividades de enfermagem, WOLFE; YOUNG (1965) perceberam uma estreita relação entre necessidade de cuidado direto e a condição do paciente. Estes pesquisadores propuseram uma classificação com base no grau de auto-suficiência do paciente em 3 categorias: auto-cuidado, cuidado parcial e cuidado total. Os dados referentes à quantidade média de cuidados diretos de enfermagem promovidos ao paciente em cada categoria possibilitaria a determinação da quantidade total de cuidado direto necessário em uma determinada unidade de enfermagem.

Esta primeira geração de SCP, desenvolvida ao longo dos anos 60, teve como objetivo fundamental prever o dimensionamento de pessoal de enfermagem por plantão e unidade.

A partir dos anos 70 houve uma proliferação de sistemas de classificação. Uma contagem não oficial, em 1979, reportava cerca de 1000 hospitais nos Estados Unidos usando algum tipo de SCP (GIOVANNETTI , 1979).

Essencialmente são duas as estruturas básicas destes instrumentos de classificação: 1- Sistema Protótipo ou Avaliação Protótipo descreve as características típicas de pacientes para cada categoria. Este modelo embora facilmente exequível apresenta certo subjetivismo; 2- Sistema Avaliação de Indicadores estabelece um número de prognosticadores de cuidados diretos de enfermagem tais como: higiene, nutrição, eliminações, movimentação, etc , que são avaliados separadamente e depois combinados para formar uma categoria de cuidado ao paciente. Este tipo de instrumento é de uso mais difundido e referido como mais 
objetivo (GIOVANNETTI, 1979; VAUGHAN; MACLEOD, 1980; REINERT; GRANT, 1981; DIJKERS; PARADISE, 1986; WILLIAMS; ANDERSON,1992).

Segundo GIOVANNETTI (1979) o uso da terminologia subjetivo, para avaliação protótipo, e objetivo para avaliação de indicadores é inadequado, pois um certo grau de subjetividade sempre permeia a avaliação das necessidades de cuidado de enfermagem. Estes modelos de instrumento de classificação constituem a segunda geração de SCP.

Em 1981 a Joint Comission on Accreditation of Hospitals (JCAH), comissão que avalia os padrões de assistência dos hospitais nos Estados Unidos, propôs aos departamentos de enfermagem definir, implementar e manter um sistema para determinar as necessidades de cuidado de enfermagem do paciente. Dessa forma, os hospitais foram compelidos a desenvolver e implementar SCP na tentativa de solucionar o problema de alocação de pessoal de enfermagem (ALWARD, 1983; DIJKERS;PARADISE, 1986)

Pressões econômicas para o controle de custos na área hospitalar, nos Estados Unidos, expandiram os objetivos dos SCP. Os gerentes de enfermagem passaram a utilizá-lo, não tão somente para nortear o processo decisório relacionado à alocação de pessoal de enfermagem, mas também, para monitorar níveis de produtividade, determinar custos do Serviço de Enfermagem e garantir assistência de qualidade (ALWARD,1983; DE GROOT, 1989a).

Problemas críticos referentes ao uso inadequado do SCP foram enfocados por vários autores na literatura norte-americana. Alguns, apontavam o número reduzido de categorias (4 a 5) como fator limitante para englobar a variabilidade do grau de complexidade dos pacientes (DIJKERS; PARADISE, 1986). 
Outros, comentavam a inexistência de uma clara distinção entre as categorias conduzindo à interpretações subjetivas (VAUGHAN; MACLEOD,1980). AYDELOTTE (1973) e BARHAM; SCHNEIDER (1980) mencionavam que os instrumentos existentes se atinham exclusivamente a abordagem de necessidades fisiológicas não contemplando a dimensão psicossocial, como suporte emocional e ensino. Para VAN SLYCK (1991) uma das falhas do SCP estava na estrutura do sistema baseada na execução de atividades selecionadas e cronometradas, perpetuando o mito da enfermeira como mera cumpridora de tarefas. HAAS (1988) questionou a inexistência de uma teoria de enfermagem que embasasse os sistemas de classificação vigentes.

Alguns instrumentos para classificação de pacientes desenvolvidos e implementados em determinadas organizações de saúde passaram a ser aplicados em outras instituições sem que ocorresse uma confirmação de sua validade e confiabilidade (VAUGHAN; MACLEOD, 1980; WHITNEY; KILLIEN, 1987; WILLIAMS, 1988) e esta inobservância da dependência contexto-institucional do instrumento, aliada às limitações da capacidade de mensuração que qualquer instrumento traz em si mesmo, preocupou alguns autores como GIOVANNETTI (1979), WHITNEY; KILLIEN (1987), HAAS (1988), WILLIAMS (1988) e DE GROOT (1989b). Estas pesquisadoras recomendaram a utilização de métodos para monitorar continuamente a validade e confiabilidade do instrumento de classificação.

PHILLIPS et al (1992) realizando um estudo comparativo entre dois SCP muito conhecidos e utilizados nos Estados Unidos, Medicus e GRASP, e o PINI (Patient Intensity for Nursing Index), instrumento utilizado para mensuração do custeio dos serviços de enfermagem, concluiu que os SCP não mediam os recursos 
necessários à assistência da mesma forma. Os SCP existentes, até então, por medirem a estimativa da assistência de enfermagem necessária e não da assistência efetivamente promovida, introduzia erros sistemáticos nas medidas de custo da assistência de enfermagem .

Uma nova segunda geração de sistema de classificação foi descrita por GIOVANNETTI; JOHNSON (1990). Trata-se do ARIC (Allocation , Resource, Identification and Costing), um sistema computadorizado com monitorização de confiabilidade e validade. Este instrumento emprega uma combinação de etapas para a classificação do paciente iniciando com a descrição dos cuidados dependentes, representados pelo esquema terapêutico do paciente na unidade. A média de hora de assistência de enfermagem é, então, estabelecida sendo depois realizada a descrição dos cuidados independentes constituídos pelas necessidades psicossociais e educacionais do paciente/família. A combinação dos cuidados dependentes e independentes conduz à uma única classe ou categoria.

No Brasil, uma das primeiras autoras a tratar de sistema de classificação de pacientes foi RIBEIRO (1972). Em seu estudo a autora apontou o conceito de Cuidado Progressivo dos Pacientes (CPP) como um método para instrumentalizar o dimensionamento de recursos humanos em enfermagem com vistas a assegurar uma distribuição mais equitativa da assistência, aumento da produtividade e eficiência hospitalar.

Com o surgimento desta sistemática de assistência embasada no CPP, criou-se a necessidade de se determinar indicadores para estabelecer a classificação de pacientes. Tais indicadores serviam como parâmetro para orientar a admissão e rotatividade de pacientes nas áreas do CPP. 
OLIVEIRA; ROMÁN (1976) relataram uma experiência na análise do perfil dos pacientes, internados em um hospital de ensino na Universidade da Bahia, identificando os indicadores: compulsórios, específicos da Unidade de Tratamento Intensivo e Unidade de Cuidados Intermediários, tais como: uso de respirador, sinais vitais de 2/2 horas, inconsciência, locomoção e alimentação com ajuda parcial; moderados, comuns às duas áreas, como uso de oxigênio, presença de infusão, repouso no leito e outros e contra-indicadores de cuidados intensivos, próprios da Unidade de Cuidados Mínimos, “todos os demais critérios”.

Alegando a inexistência de critérios oficiais para calcular pessoal de enfermagem, ALCALÁ et al (1982) apresentaram contribuição significativa, propondo parâmetros para lotação de pessoal nas Unidades Médico-Hospitalares da Superintendência da Secretaria de Higiene e Saúde. Para tanto, utilizaram o método da assistência progressiva. Relataram que no decorrer do trabalho sentiram a necessidade de adicionar a categoria cuidado semi-intensivo para "caracterizar o nível de atenção frequentemente requerido por pacientes, que não se enquadram nem em cuidados intensivos e nem em intermediários".

No trabalho de LIMA (1985), nota-se a preocupação em determinar o tempo médio dispensado, nas 24 horas, para o cuidado direto de enfermagem a pacientes com menor nível de complexidade assistencial, em uma Unidade de Clínica Médica.

Em seu estudo sobre cálculo de pessoal, realizado no Hospital Universitário da USP de São Paulo, CAMPEDELLI et al (1987) utilizaram três diferentes índices como propostos por Abboud, Alcalá et al e do próprio Hospital Universitário. Os resultados evidenciaram a necessidade de se realizar a 
classificação de pacientes nas unidades, por tipo de cuidado, como forma de determinar as necessidades de assistência de enfermagem mais compatíveis à realidade.

Pesquisas sobre dimensionamento de pessoal de enfermagem utilizando o SCP foram também desenvolvidas por ALVES et al (1988) e SANTOS (1992). BENKO et al (1992) utilizaram o SCP junto à clientela dos serviços de saúde ambulatorial.

RODRIGUES FILHO (1992) enfatizou a importância da utilização deste sistema como parâmetro para o processo decisório em relação ao dimensionamento de recursos humanos em enfermagem, recomendando a inclusão deste tema nas áreas de pesquisa em enfermagem no Brasil.

O Hospital Municipal Arthur Ribeiro de Saboya, na cidade de S.Paulo, na década de 80, objetivando ministrar assistência integral e individualizada ao paciente desenvolveu um processo de classificação e agrupamento de pacientes embasado no cuidado progressivo. Os pacientes foram classificados de acordo com indicadores pré-estabelecidos pela equipe de enfermeiros deste hospital em 4 níveis de atenção: cuidados mínimos, cuidados intermediários, cuidados semi-intensivos e cuidados intensivos (REIS et al ,1982).

Mais recentemente, em uma experiência de implantação de um SCP na Unidade de Clínica Médica do Hospital Universitário da USP relatada por FUGULIN et al (1994), os pacientes foram organizados em cinco categorias de acordo com sua complexidade assistencial em : intensivo, semi-intensivo, alta dependência, intermediário e auto-cuidado. As autoras introduziram, no estudo, a categoria alta dependência para classificar os pacientes "crônicos que requeiram 
avaliações médicas e de enfermagem, estável sob ponto de vista clínico, porém, com total dependência das ações de enfermagem quanto ao atendimento das necessidades humanas básicas." Como resultados da implementação desta sistemática, dentre outros, houve um decréscimo na média de permanência hospitalar do paciente, melhoria dos padrões de qualidade assistencial e a utilização mais racional dos recursos humanos e materiais disponíveis.

ROMERO et al ( 1994) desenvolveram, no Hospital Evaldo Foz, São Paulo, um instrumento para classificação dos cuidados de enfermagem quanto ao grau de dependência. Os autores consideraram que existe a necessidade de novas reavaliações deste instrumento para que se verifique possíveis distorções em sua aplicação.

Paralelamente, RAMOS et al ( 1994) instituíram no hospital Israelita Albert Einstein, um sistema próprio de classificação, elaborando um instrumento composto por 9 parâmetros passíveis de classificaçãoem 3 níveis de dependência.

A OPAS/OMS em sua preocupação em implementar e garantir a qualidade nos hospitais latino-americanos, propôs a utilização de programas de Acreditação. Em seu manual, mencionou a categorização como um método a ser utilizado para classificação de serviços de acordo com critérios como risco de atenção (NOVAES, 1994). Esta menção poderia estar sugerindo a utilização de um sistema de classificação de pacientes.

O COFEN (1996), considerando a inexistência de uma regulamentação da proporção profissionais / leitos para assistência de enfermagem ao paciente, na resolução 189 estabeleceu parâmetros mínimos para o dimensionamento do quadro de profissionais de enfermagem nas Instituições de Saúde. De acordo com 
este documento o cálculo de pessoal de enfermagem deve ser embasado no SCP e a proporção dos elementos da equipe de enfermagem distribuída em percentuais determinados nos diferentes tipos de cuidados: mínimo ou auto-cuidado, intermediário, semi-intensivo e intensivo. O COFEN estabeleceu, ainda, que a classificação dos pacientes para implementação da assistência de enfermagem será de competência do enfermeiro.

No desempenho de minhas atividades profissionais, ora como docente, ora com enfermeira assistencial, atuando em diversas unidades, tenho observado a inadequação qualitativa e quantitativa dos recursos humanos em enfermagem para o atendimento das necessidades dos pacientes de acordo com sua complexidade assistencial. Isto tem acarretado insatisfações tanto à clientela utilizadora dos serviços da Instituição como ao próprio pessoal de enfermagem pelo desgaste e estresse constantes.

Ao assumir a gerência de enfermagem de um hospital de grande porte tentei utilizar meu conhecimento, habilidade e capacidade para organizar o Serviço de Enfermagem. A distribuição efetiva de pessoal era o aspecto que mais requeria minha atenção. Como justificar ao administrador hospitalar a necessidade de maior contingente de pessoal quando o número de leitos ocupados permanecia o mesmo ? Que argumentos utilizar, e embasados em quais critérios de dimensionamento de pessoal, para garantia de padrões de qualidade no processo de cuidar ? Estes questionamentos durante muito tempo permaneceram sem resposta.

Durante o Curso de Pós-Graduação nível Mestrado da EEUSP, tive oportunidade de entrar em contato com a proposta de SCP, sistemática em que a gravidade do paciente é a essência, e não o valor numérico de pacientes na unidade. 
Esta metodologia respondia, em parte, minhas indagações . O SCP, enquanto consistente base de dados, favorece os gerentes de enfermagem, dentre outros aspectos, em subsidiar suas justificativas quanto às necessidades de pessoal. Este enfoque despertou meu interesse em aprofundar a investigação sobre esta temática.

Assim, neste estudo, proponho-me a elaborar um instrumento para classificação de pacientes capaz de reconhecer o perfil da clientela usuária dos serviços de saúde hospitalar. Estimamos que este instrumento se mostre adequado ao contexto nacional na tentativa de contribuir para a minimização do antigo problema, constituindo-se em um primeiro passo para o dimensionamento do pessoal de enfermagem, bem como para servir de base para posteriores análises de custos da assistência. 


\section{OBJETIVOS}

1-Identificar os indicadores críticos essenciais à classificação de pacientes.

2-Construir um instrumento para classificação baseado nas necessidades individualizadas de cuidado de enfermagem do paciente cujas características sejam objetividade, simplicidade e abrangência.

3-Validar o conteúdo do instrumento de classificação de pacientes . 


\section{MÉTODO}

A abordagem metodológica, neste estudo, seguiu as seguintes etapas : construção do instrumento de classificação de pacientes, utilização de técnica para validação do intrumento de classificação de pacientes e estabelecimento de método para padronização do escore.

\subsection{Construção do Instrumento de Classificação de}

\section{Pacientes}

A construção do instrumento para classificação de pacientes fundamentou-se em extenso levantamento bibliográfico sobre a implementação de modelos operacionais de SCP (CHAGNON et al, 1978; BARHAM;SCHNEIDER, 1980; REINERT;GRANT, 1981; HUCKABAY, 1981; JACKSON; RESNICK, 1982; WHITNEY; KILLIEN, 1987; GIOVANNETTI; JOHNSON, 1990; WILLIAMS; ANDERSON, 1992; BENKO et al, 1991 ; FUGULIN et al, 1994 ).

Considerando os enfoques dos diversos autores, optou-se pela elaboração de um instrumento cuja estrutura seja a avaliação de indicadores baseados nas necessidades humanas básicas preconizadas por HORTA (1979).

Desta forma, para compor o instrumento de classificação de pacientes são considerados 13 indicadores críticos :

\section{I - Estado Mental e Nível de Consciência \\ II - Oxigenação}


III - Sinais Vitais

IV - Nutrição e Hidratação

$V$ - Motilidade

$V I$ - Locomoção

VII - Cuidado Corporal

VIII - Eliminações

IX -Terapêutica

X-Educação à Saúde

$X I$-Comportamento

XII - Comunicação

XIII - Integridade Cutâneo- Mucosa

Adotaremos a terminologia indicadores críticos, neste instrumento de classificação, para nos referirmos às necessidades de cuidado de enfermagem do paciente que, quando associadas entre si, identificam a categoria de cuidado a que ele pertence.

Cada um destes indicadores possui gradação de 1 a 5 apontando a intensidade crescente de complexidade, de forma que o valor 1 corresponde ao menor nível de atenção de enfermagem e o valor 5 ao nível máximo de complexidade assistencial.

O paciente é classificado em todos os indicadores em um dos 5 níveis, na opção que melhor descreva a sua situação. 
Os valores obtidos individualmente, em cada indicador, são então somados conduzindo a uma classe ou categoria de cuidados, tais como: cuidados mínimos, cuidados intermediários, cuidados semi-intensivos e cuidados intensivos.

\subsection{Técnica de Validação do Instrumento de}

\section{Classificação de Pacientes}

Na fase de estruturação e desenvolvimento de um instrumento para classificação de pacientes estabelecer e monitorar a confiabilidade e a validade são questões essenciais (GIOVANNETTI, 1979; GIOVANNETTI;MAYER, 1984; WHITNEY;KILLIEN, 1987; HAAS, 1988; WILLIAMS, 1988; DE GROOT, 1989b).

De acordo com estes autores, um instrumento apresenta confiabilidade quando revela o mesmo resultado em classificações repetidas, no mesmo paciente, ou quando utilizado por diferentes avaliadores. Validade refere-se à precisão do instrumento em medir o que se propõe a medir.

Para que um instrumento seja considerado válido é necessário que ele seja também confiável. Contudo, um instrumento que se mostre apenas confiável pode não ser válido (GIOVANNETTI;MAYER, 1984; WHITNEY;KILLIEN, 1987; HAAS, 1988). A validade de um instrumento é um aspecto de difícil mensuração.

De acordo com WHITNEY; KILLIEN (1987), a estimativa da confiabilidade e da validade de um SCP pode ser determinada quando : 1-um novo sistema está sendo desenvolvido; 2- após sua implementação, em intervalos regulares, para monitorar o seu correto uso; 3- ou ainda quando um sistema existente 
é modificado para se adaptar às novas exigências do serviço ou para ser utilizado em outro local.

Para GIOVANNETTI (1979), a mais importante estimativa de confiabilidade é representada pela equivalência, ou seja, a consistência que o instrumento apresenta entre várias aplicações. Quando duas ou mais enfermeiras classificam o mesmo paciente e seus resultados são comparados, isto é referido como "confiabilidade entre avaliadores" (interrater reability). A comparação dos resultados pode ser efetuada entre as enfermeiras da mesma unidade, de unidades diferentes ou ainda entre enfermeiras que atuam em diferentes instituições.

Diferenças nos resultados entre classificações podem ocorrer quando as enfermeiras emitem julgamentos utilizando seus critérios individuais. Esta questão pode ser corrigida quando os indicadores críticos estão bem definidos no instrumento (WILLIAMS, 1988).

A confiabilidade pode ser medida em coeficientes. Altos coeficientes de confiabilidade entre avaliadores garantem a mesma classificação do paciente por diferentes enfermeiras avaliadoras. Isto não significa, no entanto, uma garantia de confiabilidade duradoura do instrumento. Programas de educação continuada constituem o meio mais efetivo para garantia de altos coeficientes de confiabilidade entre avaliadores (GIOVANNETTI,1979).

GIOVANNETTI (1979), GIOVANNETTI; MAYER (1984), WHITNEY; KILLIEN (1987), HAAS (1988) e WILLIAMS (1988) consideram a validade de conteúdo e a validade relacionada à critérios como os tipos mais comuns de validade. 
A validade de conteúdo envolve o julgamento, por enfermeiros com vasta experiência profissional, dos indicadores críticos contidos no instrumento, para analisar se estes indicadores são representativos do que se pretende medir.

A validade relacionada a critérios significa a correlação do desempenho de uma medida quando comparada com outra medida ou critério. A primeira medida será considerada válida se a correlação com as medidas de critério for elevada. Este tipo de validade pode apresentar duas formas: concorrente e preditiva (WILLIAMS,1988).

A validade concorrente é estabelecida por análise comparativa entre um novo instrumento de classificação e um outro já estabelecido e validado (GIOVANNETTI,1979; WILLIAMS,1988).

A validade preditiva é utilizada para testar o valor prático do instrumento verificando se ele prediz, com precisão, uma ocorrência futura. No SCP esta medida indica se a classificação de pacientes adequadamente estima o quadro de pessoal de enfermagem necessário para o cuidado (GIOVANNETTI,1979; GIOVANNETTI; MAYER,1984; WHITNEY; KILLIEN,1987; WILLIAMS,1988).

FEHRING (1987) desenvolveu dois modelos para validação de diagnóstico de enfermagem que têm sido largamente utilizado por enfermeiras nos Estados Unidos. Este modelo apresenta duas diferentes formas de obtenção de fontes de evidência: a opinião de enfermeiros com vasta experiência profissional ( Validação de Conteúdo) e a observação clínica diretamente do paciente (Validação Clínica).

Na presente pesquisa optou-se pelo método da validação do conteúdo do instrumento de classificação através da aplicação da Técnica Delphi com o 
objetivo de avaliar a extensão da dependência do paciente com relação à assistência de enfermagem.

A Técnica Delphi consiste na solicitação, coleta, tabulação e avaliação de dados a respeito de um determinado fenômeno por meio da opinião de um grupo de especialistas na área onde o estudo está sendo desenvolvido (FARO,1995).

Esta técnica tem sido aplicada em vários campos tais como economia, educação, dentre outros, e vem sendo crescentemente empregada em pesquisas de enfermagem. GRANT; KINNEY (1992) utilizaram esta técnica para validação do conteúdo de diagnósticos de enfermagem.

SPÍNOLA (1984) e WILLIAMS; WEBB (1994) apresentaram algumas vantagens que recomendam a utilização da Técnica Delphi : 1- eliminação da influência da interação direta entre as pessoas ; 2 - estabelecimento de comunicação entre pessoas distantes geograficamente; 3 - produção de grande quantidade de idéias de alta qualidade e especificidade ; 4 - baixo custo para operacionalização.

O instrumento utilizado para a produção de informações consiste em um conjunto seqüencial de questionários de forma que as primeiras respostas obtidas são consideradas para reformulação e obtenção das respostas subsequentes até que se alcance um consenso. O número de questionários aplicados está na dependência de alguns fatores como a natureza do tema e a sua complexidade (SPÍNOLA,1984).

Cabe ao pesquisador estabelecer o nível de consenso aceitável. WILLIAMS; WEBB (1994) comentam que a falta de uma clara especificação do nível de consenso antes do envio dos questionários ao grupo de juízes favorece a influência da interpretação pessoal do investigador nos resultados obtidos. É 
recomendado, na etapa final da Técnica Delphi, um nível mínimo de concordância de 70\% (GRANT; KINNEY, 1992).

A primeira etapa da Técnica Delphi consiste no processo de seleção do grupo de peritos. Ainda de acordo com SPÍNOLA (1984), não existe um número ideal estabelecido de informantes. Para determinação de seu total são levados em conta fatores como custo, natureza do problema e o número de peritos disponíveis para o tema em estudo.

Desta forma, nesta pesquisa, a Técnica Delphi foi aplicada em duas fases ( Fase Delphi I e Fase Delphi II) seguindo as etapas :

1-elaboração dos critérios para seleção dos juízes - foram convidados para atuarem como juízes 15 profissionais da área de enfermagem que correspondessem aos seguintes critérios: 1- ter experiência profissional, de pelo menos 5 anos, nas áreas de enfermagem cirúrgica, clínica, pediátrica ou ginecoobstétrica ; 2- atuar junto a instituições de assistência ou vinculados a HospitalEscola na cidade de São José do Rio Preto.

Dessa forma, a seleção do grupo de profissionais que participaram desta pesquisa iniciou-se pela identificação dos enfermeiros atuantes nas diversas organizações de saúde e ensino da cidade de São José do Rio Preto.

Através de contatos pessoais procurou-se verificar se estes profissionais atendiam aos critérios já descritos anteriormente para compor o grupo de juízes. Verificada a possibilidade de inclusão no estudo, foi feito convite às enfermeiras e, após anuência destas, procedeu-se à orientação com respeito às etapas da pesquisa e a forma como atuariam na mesma. 
Para julgamento do indicador Comportamento foram convidados 2 profissionais da área de Psicologia Clínica com mais de 5 anos de atuação profissional que avaliaram a clareza e pertinência do conteúdo deste indicador. Estes profissionais sugeriram que fossem feitas alterações no sentido de melhor definir a terminologia utilizada e a forma como avaliar os comportamentos observáveis dos pacientes.

2-elaboração do questionário - O questionário (ANEXO1) foi composto de dados referentes à identificação, área de atuação e qualificação profissional dos juízes e por duas partes relativas à estruturação do instrumento de classificação de pacientes. Na parte I foram apresentados os 13 indicadores críticos que compõem o instrumento, cabendo aos juízes, através de questões fechadas em 2 alternativas, SIM e NÃO, julgarem a pertinência de cada indicador no instrumento. Após estas alternativas deixou-se um espaço para que os juízes pudessem registrar os comentários que achassem necessários. A parte II do questionário referiu-se à classificação dos indicadores. Nesta parte, coube aos juízes a apreciação sobre cada indicador no que diz respeito ao conteúdo, seguimento de um nível de complexidade assistencial crescente e clareza nos enunciados, assinalando SIM ou NÃO para cada um dos tópicos. Reservou-se, também, espaço para que os juízes pudessem acrescentar algum comentário que julgassem pertinente. O questionário foi acompanhado de uma carta explicativa esclarecendo sobre os objetivos da pesquisa, bem como as atividades solicitadas, aos juízes, pela pesquisadora. Os comentários registrados foram considerados para a elaboração do segundo questionário (ANEXO 2). Estes questionários foram entregues, pela pesquisadora, sendo estabelecido um prazo de 10 dias para o retorno. 
3-estabelecimento do índice de concordância para as respostas obtidas - foram considerados como validados os indicadores que obtiveram índice de concordância nas respostas dos juízes maior ou igual a $70 \%$.

\section{4- tabulação dos dados e análise da opinião convergente dos}

juízes- os dados obtidos no primeiro questionário foram tabulados e tratados percentualmente para verificar se o índice de concordância encontrado era maior ou igual a $70 \%$, tanto na parte I, relacionada ao número dos indicadores, como na parte II, relacionada ao conteúdo, nível de complexidade assistencial crescente e clareza.

\subsection{Método para Padronização do Escore}

Considerando os 13 indicadores críticos que compõem o instrumento para classificação de pacientes, com cada indicador variando de uma pontuação de 1 a 5, a pontuação mínima a ser alcançada será de 13 pontos e a máxima de 65 pontos, com amplitude total igual a 52 pontos.

Os pontos foram distribuídos em 4 categorias (classes) com intervalos de classe igual a 12, adaptados do conceito de FUGULIN et al (1994), correspondentes aos tipos de cuidados: mínimos, intermediários, semi- intensivos e intensivos.

Definindo-se como: 
Cuidados Mínimos - cuidados a pacientes estáveis sob o ponto de vista clínico e de enfermagem, mas fisicamente auto-suficientes quanto ao atendimento das necessidades humanas básicas;

Cuidados Intermediários - cuidados a pacientes estáveis sob o ponto de vista clínico e de enfermagem, com parcial dependência das ações de enfermagem para o atendimento das necessidades humanas básicas;

Cuidados Semi-Intensivos - cuidados a pacientes recuperáveis ou crônicos, estáveis sob o ponto de vista clínico e de enfermagem, porém, com total dependência das ações de enfermagem quanto ao atendimento das necessidades humanas básicas;

Cuidados Intensivos - cuidados a pacientes graves, com risco iminente de vida, sujeitos à instabilidade de sinais vitais, que requeiram assistência de enfermagem e médica permanente e especializada;

Dessa forma, obteve-se um escore padronizado à cada categoria de cuidado, conforme esquema abaixo :

\section{CATEGORIAS}

Cuidados Mínimos

Cuidados Intermediários

Cuidados Semi- Intensivos

Cuidados Intensivos

\section{PONTUAÇÃO}

13 a 26 pontos

27 a 39 pontos

40 a 52 pontos

53 a 65 pontos 
O número de pacientes pertencentes a cada categoria de cuidado é dado através da distribuição da frequência da categoria na unidade em estudo. Assim sendo, a enfermeira após categorizar os pacientes deverá estabelecer a distribuição da freqûencia de cada categoria ( tipo de cuidado), conforme quadro a seguir :

\begin{tabular}{|l|ll|}
\hline CATEGORIAS & PONTUAÇÃO & N \\
\hline Cuidados Mínimos & 13 a 26 pontos & $\mathrm{f} 1$ \\
\hline Cuidados Intermediários & 27 a 39 pontos & $\mathrm{f} 2$ \\
\hline Cuidados Semi- Intensivos & 40 a 52 pontos & $\mathrm{f} 3$ \\
\hline Cuidados Intensivos & 53 a 65 pontos & $\mathrm{f} 4$ \\
\hline TOTAL & & $\sum \mathrm{f} \mathrm{i}=\mathrm{N}$ \\
\hline
\end{tabular}




\section{CONSTRUINDO OS RESULTADOS}

O presente instrumento de classificação de pacientes, baseado nas necessidades humanas básicas preconizadas por HORTA (1979), foi elaborado a partir de levantamento da literatura, e está constituído por 13 indicadores críticos com gradação de complexidade assistencial descrita de 1 a 5 .

1 - Estado Mental e Nível de Consciência (habilidade em manter a percepção e as atividades cognitivas) FARIAS (1990); KOIZUME (1990); KOIZUME et al (1994); FUGULIN et al (1994)

1- Acordado ; interpretação precisa do ambiente ; executa corretamente ordens verbalizadas ; preservação da memória .

2- Acordado ; interpretação precisa do ambiente ; interpretação errada de informações ; dificuldades de memória

3- Acordado ; interpretação imprecisa do ambiente em alguns momentos ; dificuldade em seguir instruções ; dificuldade aumentada de memória

4- Acordado ; interpretação imprecisa do ambiente em todos os momentos; não segue instruções; perda de memória

5 -Desacordado ; ausência de resposta verbal e manutenção de respostas à estímulos dolorosos ou ausência de respostas verbais e motoras 
2 - Oxigenação (aptidão em manter a permeabilidade das vias aéreas e o equilíbrio nas trocas gasosas por si mesmo, com auxílio da equipe de enfermagem e/ou de equipamentos) CHAGNON et al (1978); BENKO et al (1991);FUGULIN et al (1994)

1- Não depende de oxigenoterapia

2- Uso intermitente ou contínuo de oxigênio

3- Necessita aspiração de secreções traqueobrônquicas

4- Traqueostomia ou tubo endotraqueal com ou sem nebulização

5- Ventilação mecânica

3 - Sinais Vitais (necessidade de observação e de controle dos parâmetros vitais: temperatura corporal, pulsos, padrão respiratório e pressão sanguínea) CHAGNON et al (1978); BARHAM ; SCHNEIDER (1980); REINERT;GRANT (1981); GIOVANNETTI ; JOHNSON (1990) ; BENKO et al (1991); FUGULIN et al (1994)

1- Controle de sinais vitais de rotina ( 8 horas )

2- Controle de sinais vitais em intervalos de 6 horas

3- Controle de sinais vitais a cada 4 horas

4- Controle de sinais vitais a cada 2 horas

5- Controle de sinais vitais em intervalo menor do que 2 horas

4 - Nutrição e Hidratação (habilidade de ingerir nutrientes e líquidos para atender às necessidades metabólicas, por si mesmo, com auxílio de outros ou por meio de sondas e catéteres) CHAGNON et al (1978); BARHAM; SCHNEIDER (1980); FUGULIN et al (1994)

1- Auto-suficiente e hidratação oral ou dieta zero

2- Por boca, com auxílio; perfusão EV de 24 horas 
3- Por boca, com auxílio; precisa encorajamento

4- Através de SNG ou enteral

5- Alimentação parenteral ( simples ou catéter central )

5 - Motilidade (capacidade de movimentar os segmentos corporais de forma independente, com auxílio da equipe de enfermagem ou pelo uso de artefatos) ${ }^{\text {FARIAS }}$ (1990); FUGULIN et al (1994); FARO (1995)

1- Movimenta sozinho todos os segmentos corporais

2- Requer uso de artefatos para movimentação de qualquer segmento corporal

3- Requer auxílio de terceiros para assistência, supervisão ou ensino na movimentação de qualquer segmento corporal ou requer auxílio de terceiros e uso de artefatos para a movimentação de qualquer segmento corporal

4- Incapacidade para movimentar segmentos corporais por presença de aparelhos gessados, tração , fixador externo e outros

5- Incapacidade para movimentar qualquer segmento corporal

6 - Locomoção (habilidade para movimentar-se dentro do ambiente físico por si só, com auxílio de terceiros ou pelo uso de artefatos) CHAGNON et al (1978); BARHAM; SCHNEIDER (1980); FUGULIN et al (1994); FARO (1995)

1- Ambulante

2- Necessita encorajamento para deambular

3- Necessita auxílio de outros para deambulação

4- Locomoção através de cadeira de rodas ou outros artefatos

5- Restrito ao leito 
7 - Cuidado Corporal (capacidade para realizar por si mesmo ou com auxílio de outros, atividades de higiene pessoal, de vestir-se e arrumar-se) CHAGNON et al (1978); BARHAM; SCHNEIDER (1980); REINERT; GRANT (1981); FUGULIN et al (1994)

1- Auto-suficiente

2- Necessita auxílio na higiene íntima

3- Necessita auxílio no banho de chuveiro e/ou na realização de higiene oral

4- Banho no chuveiro em cadeira de higiene com auxílio; higiene oral realizada pela enfermagem

5- Banho no leito; higiene oral realizada pela enfermagem

8 - Eliminações (habilidade em manter eliminações urinária e intestinal sozinho, com auxílio de terceiros ou por drenos e estoma) CHAGNON et al (1978); BARHAM; SCHNEIDER (1980); BENKO et al (1991); FUGULIN et al (1994)

1- Auto-suficiente

2- Uso de vaso sanitário com auxílio de enfermagem

3- Uso de comadre com eliminações no leito ou uso de fraldas

4- Irrigação vesical ou urostomia ou colostomia ou ileostomia

5- Evacuação no leito e presença de cateter vesical ou dispositivo para incontinência urinária

9 - Terapêutica (utilização dos diversos agentes terapêuticos prescritos) CHAGNON et al (1978); BARHAM; SCHNEIDER (1980); REINERT; GRANT (1981); JACKSON;RESNICK (1982); GIOVANNETTI; JOHNSON (1990); BENKO et al (1991); FUGULIN et al (1994) 
1- VO de rotina ou IM

2- EV intermitente

3- EV contínua ou através de SNG

4- Uso de sangue e derivados ; expansores plasmáticos

5- Uso de drogas vasoativas

10 - Educação à Saúde (habilidade do paciente/família para manutenção dos hábitos de saúde pessoais e/ou ambientais) CHAGNON et al (1978); BARHAM;SCHNEIDER (1980); REINERT;GRANT (1981); NEVES (1987); FARIAS (1990); BENKO et al (1991); ZAGO (1993)

1- Orientações ao paciente/família sobre rotinas hospitalares e atividades diárias ou não tem condições para receber orientações

2- Orientações ao paciente/família sobre cuidados perioperatórios ou procedimentos diagnósticos

3- Orientações ao paciente/família sobre auto-cuidado com pronta compreensão 4- Orientações ao paciente/família apreensivos ou resistentes sobre auto-cuidado 5- Orientações ao paciente/família com severas reações emocionais sobre autocuidado

11 - Equilíbrio Comportamental (sentimentos, pensamentos e condutas do paciente gerados em sua interação com a equipe de saúde e/ou família) CABRAL;NICK (1979); BARHAM; SCHNEIDER (1980); FILLIOUD et al (1981); DICIONÁRIO Médico Blakiston (1982); JACKSON; RESNICK (1982); PIÉRON (1987); FARIAS (1990); CASSEM (1991); ROSEMBAUM; POLLACK (1991); TAYLOR (1992); DSM-IV (1995)

Para preencher o indicador abaixo observe as conceituações : 
ANSIEDADE - "vago sentimento de catástrofe iminente, apreensão ou sensação de pavor" (TAYLOR, 1992).

SINTOMAS DE ANSIEDADE - alteração da respiração, tremores, sudorese, taquicardia, náusea, vômito,vertigem, anorexia, diarréia, inquietação, perturbação do sono, medo excessivo ou irracional, sensações de falta de ar ou sufocamento, parestesias, tensão muscular( DSM-IV,1995).

RETRAIMENTO SOCIAL - tendência ocasional para evitar contatos sociais ; funcionamento social diminuido.

IRRITABILIDADE - "Irritação : estado relativamente moderado de cólera, expressando-se sobretudo em formas verbais"( CABRAL;NICK,1979). Ex: exasperação, exaltação.

RETRAIMENTO SOCIAL AUMENTADO - tendência frequente para evitar contatos sociais.

APATIA -"aparente insensibilidade a tudo o que provoca habitualmente no indivíduo um sentimento ou uma emoção" (FILLIOUD et al, 1981), indiferença. Ex: não manifestação de amor, ódio, alegria, tristeza, medo, raiva.

PASSIVIDADE - "é uma predisposição para sofrer sem iniciativa nem esforço todas as influências exteriores" (FILLIOUD et al, 1981). Ex: Não reação diante de procedimentos de enfermagem, condutas médicas, hospitalização.

DESESPERANÇA - " estado subjetivo em que o indivíduo vê escolhas pessoais disponíveis limitadas, ou sem alternativas, e está incapaz de mobilizar energia em seu próprio favor" (NANDA, 1986). Ex: ausência ou diminuição de expectativas, projetos e planos de vida.

IMPOTÊNCIA PSÍQUICA - " percepção de que uma pessoa tem de que o que ela pode fazer não altera, significativamente, um resultado ..." ( NANDA, 1982). Ex: demonstração de incapacidade para desempenhar atividades cotidianas ( "não sei", "não vou conseguir", "não posso").

AMBIVALENCIA DE SENTIMENTOS - " coexistência de dois impulsos, desejos, atitudes ou emoções opostos dirigidos para a mesma pessoa, o mesmo objeto ou o mesmo objetivo ..." (DICIONÁRIO Médico Blakiston, 1982). Ex: afirmação/negação, aceitação/rejeição, amor/ódio, alegria/tristeza.

ISOLAMENTO SOCIAL - "privação de contatos sociais ..." (CABRAL; NICK, 1979) . 
1- Calmo, tranquilo; preocupações cotidianas

2- Alguns sintomas de ansiedade (até 3) ou queixas e solicitações contínuas ou retraimento social

3- Irritabilidade excessiva ou retraimento social aumentado ou apatia ou passividade ou queixas excessivas

4- Sentimento de desesperança ou impotência psíquica ou ambivalência de sentimentos ou acentuada diminuição do interesse por atividades ou aumento da frequência de sintomas de ansiedade (mais de 3 sintomas)

5- Comportamento destrutivo dirigido a si mesmo e aos outros ou recusa de cuidados de atenção à saúde ou verbalizações hostis e ameaçadoras ou completo isolamento social

12 - Comunicação (habilidade em usar ou entender a linguagem na interação humana) REINERT; GRANT (1981); DANIEL (1983); FARIAS (1990); BENKO et al (1991)

1- Comunicativo, expressa idéias com clareza e lógica

2- Dificuldade em se expressar por diferenças sócio-culturais; verbalização inapropriada

3- Recusa-se a falar; choroso; comunicação não verbal

4- Dificuldade em se comunicar por distúrbios de linguagem ( afasia, disfasia, disartria) ou sensibilidade dolorosa ao falar ou por barreira física (traqueostomia, entubação)

5- Inapto para comunicar necessidades

13 - Integridade Cutâneo-Mucosa (capacidade em manter pele e mucosas sem

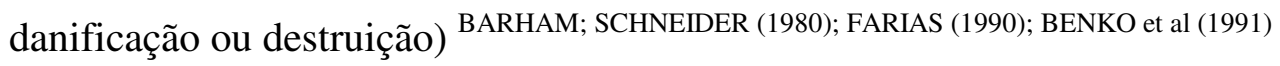


1- Pele, em uma ou mais áreas do corpo, sem solução de continuidade e sem alteração de cor

2- Presença de alteração da cor da pele (equimose, hiperemia) em uma ou mais áreas do corpo sem solução de continuidade

3- Presença de solução de continuidade em uma ou mais áreas do corpo sem presença de exsudato purulento

4- Presença de solução de continuidade em uma ou mais áreas do corpo com presença de exsudato purulento

5- Presença de solução de continuidade em uma ou mais áreas do corpo com presença de exsudato purulento, exposição de tecido muscular e ósseo ; presença de áreas de necrose

Os resultados referentes a validação do conteúdo do instrumento serão apresentados seguindo as fases em que se desenvolveu a Técnica Delphi, ou seja, Fase Delphi I e Fase Delphi II.

\subsection{Fase Delphi I}

\subsubsection{Identificação dos Juizes}

O grupo de juízes se manteve durante toda a pesquisa composto por 15 enfermeiras, das quais 8 atuam na assistência direta ao paciente, 4 atuam na docência e 3 gerenciam Serviços de Enfermagem. 
A idade das enfermeiras variou de 29 a 48 anos. Quanto ao tempo de atuação profissional, 4 enfermeiras têm de 6 a 10 anos de experiência, 6 têm de 11 a 15 anos, 4 têm de 16 a 20 anos e apenas 1 tem acima de 20 anos.

No que concerne à qualificação profissional, 6 juízes referiram ter Habilitação (4 em Enfermagem Médico-Cirúrgica e 2 em GinecoObstetrícia), 10 fizeram Especialização (4 em Enfermagem do Trabalho, 3 em Administração Hospitalar, 1 em Terapia Intensiva, 1 em Enfermagem Médico-Cirúrgica e 1 em Saúde Pública) e 2 têm título de especialista (em Enfermagem do Trabalho e Terapia Intensiva) . Um juiz referiu estar cursando Administração Hospitalar. Foi verificado, também, que 2 juízes fizeram Residência em Enfermagem e 1 tem Licenciatura. Observou-se que 4 dos juízes não têm qualquer tipo de especialização.

Quando questionados sobre pós-graduação "strictu sensu”, obteve-se a informação de que apenas 1 juiz tem título de Doutor em Enfermagem enquanto 1 juiz está cursando Mestrado.

Foram convidados, para avaliação do indicador Comportamento, dois psicólogos que possuem a seguinte qualificação : 1 com especialização em Psicologia Clínica e Doutorado, e outro com especialização em Psicologia Educacional, Doutorado e Livre Docência em Psicologia Escolar. O tempo de atuação profissional foi de 25 e 34 anos, respectivamente. 


\subsubsection{RESULTADOS}

Após a devolução dos questionários (Fase Delphi I), as respostas foram analisadas quantitativamente e as considerações dos juízes devidamente anotadas.

Apresentaremos, a seguir, os resultados obtidos, em tabelas, seguidos dos comentários dos juízes com respeito à adequação de cada indicador no instrumento, pertinência do conteúdo, clareza dos enunciados e seguimento de nível de complexidade assistencial crescente.

TABELA 1 - Pareceres dos juízes quanto à pertinência dos indicadores críticos no instrumento de classificação - Fase Delphi I . São José do Rio Preto, 1996.

\begin{tabular}{l|cccc}
\hline \multicolumn{1}{|c|}{ INDICADOR CRÍTICO } & \multicolumn{5}{c}{ P E R T I N Ê N C I A } \\
& Sim & $\%$ & Não & \% \\
\hline 1-Estado Mental e Nível de Consciência & 15 & 100 & - & - \\
2 - Oxigenação & 14 & 93,3 & 1 & 6,7 \\
3 - Sinais Vitais & 15 & 100 & - & - \\
4 - Nutrição e Hidratação & 15 & 100 & - & - \\
5 - Motilidade & 15 & 100 & - & - \\
6 - Locomoção & 15 & 100 & - & - \\
7 - Cuidado Corporal & 15 & 100 & - & - \\
8 - Eliminaçães & 15 & 100 & - & - \\
9 - Terapêutica & 13 & 86,7 & 2 & 13,3 \\
10 - Educação à Saúde & 15 & 100 & - & - \\
11 - Equilíbrio Comportamental & 15 & 100 & - & - \\
12 - Comunicação & 15 & 100 & - & - \\
13 - Integridade Cutâneo-Mucosa & 14 & 93,3 & 1 & 6,7 \\
\hline
\end{tabular}


A TABELA 1 mostra que, quando os juízes foram questionados acerca da manutenção de cada um dos 13 indicadores críticos no instrumento de classificação, houve concordância dos juízes com referência aos indicadores críticos propostos, sendo que o percentual de anuência variou de 86,7 a $100 \%$.

Como o índice de concordância para as respostas obtidas para validação do instrumento foi previamente estabelecido em maior ou igual a 70\% e o menor valor obtido foi de $86,7 \%$, todos os indicadores críticos apresentados foram considerados como validados, e, portanto, pertinentes para compor o instrumento de classificação.

O indicador crítico Equilíbrio Comportamental foi considerado por alguns juízes como de difícil abordagem devido a dificuldade da enfermeira em interpretar e avaliar as reações comportamentais do paciente. 
TABELA 2 - Pareceres dos juízes quanto à pertinência do conteúdo dos indicadores críticos do instrumento de classificação - Fase Delphi I . São José do Rio Preto, 1996.

\begin{tabular}{l|cccc}
\hline \multicolumn{1}{|c|}{ INDICADOR CRÍTICO } & \multicolumn{5}{c}{ PERTINÊNCIA DO CONTEÚDO } \\
& Sim & \% & Não & \% \\
\hline 1 - Estado Mental e Nível de Consciência & 15 & 100 & - & - \\
2 - Oxigenação & 15 & 100 & - & - \\
3 - Sinais Vitais & 14 & 93,3 & 1 & 6,7 \\
4 - Nutrição e Hidratação & 15 & 100 & - & - \\
5 - Motilidade & 15 & 100 & - & - \\
6 - Locomoção & 15 & 100 & - & - \\
7 - Cuidado Corporal & 14 & 93,3 & 1 & 6,7 \\
8 - Eliminações & 15 & 100 & - & - \\
9 - Terapêutica & 14 & 93,3 & 1 & 6,7 \\
10 - Educação à Saúde & 13 & 86,7 & 2 & 13,3 \\
11 - Equilíbrio Comportamental & 15 & 100 & - & - \\
12 - Comunicação & 15 & 100 & - & - \\
13 - Integridade Cutâneo-Mucosa & 15 & 100 & - & - \\
\hline
\end{tabular}

Conforme os dados apresentados na TABELA 2, foi possível observar que o conteúdo dos 13 indicadores críticos foi considerado como pertinente por todos os juízes ( índices iguais ou maiores que $70 \%$ ).

Os comentários dos juízes com referência ao conteúdo dos indicadores críticos foi de que: 1- fossem acrescentados ítens contemplando outros procedimentos de enfermagem (tais como, controle de sinais vitais em intervalos menores do que 2 horas, medidas de conforto, medicação intradérmica e subcutânea); 2- cuidados no uso de alguns equipamentos (como monitores de pressão arterial média e pressão venosa central, oxímetro); 3- fossem excluídos alguns procedimentos considerados não pertinentes (urostomia, colostomia, ileostomia, dieta 
zero) e outros menos abrangentes (tais como tubo endotraqueal com ou sem nebulização, aspiração de secreções traqueobrônquicas, sinais vitais de 8 horas).

Houve sugestão no sentido de se avaliar, no indicador Educação à Saúde, de um lado o tipo de orientação fornecida e do outro a possibilidade de apreensão desta orientação.

Outros juízes consideraram os indicadores críticos Equilíbrio Comportamental e Comunicação, da forma como foram apresentados, apropriados para a avaliação do paciente adulto mas não da criança. Ainda, um dos juízes recomendou a substituição do termo Equilibrio Comportamental por Comportamento. 
TABELA 3 - Pareceres dos juízes quanto à existência de nível crescente de complexidade assistencial nos indicadores críticos do instrumento de classificação - Fase Delphi I . São José do Rio Preto, 1996.

\begin{tabular}{|c|c|c|c|c|}
\hline \multirow[t]{2}{*}{ INDICADOR CRÍTICO } & \multicolumn{4}{|c|}{ GRADAÇÃO ASSISTENCIAL } \\
\hline & Sim & $\%$ & Não & $\%$ \\
\hline 1 - Estado Mental e Nível de Consciência & 15 & 100 & - & - \\
\hline 2 - Oxigenação & 13 & 86,7 & 2 & 13,3 \\
\hline 3 - Sinais Vitais & 13 & 86,7 & 2 & 13,3 \\
\hline 4 - Nutrição e Hidratação & 11 & 73,3 & 4 & 26,7 \\
\hline 5 - Motilidade & 15 & 100 & - & - \\
\hline 6 - Locomoção & 15 & 100 & - & - \\
\hline 7 - Cuidado Corporal & 13 & 86,7 & 2 & 13,3 \\
\hline 8 - Eliminações & 10 & 66,7 & 5 & 33,3 \\
\hline 9 - Terapêutica & 09 & 60 & 6 & 40 \\
\hline 10 - Educação à Saúde & 13 & 86,7 & 2 & 13,3 \\
\hline 11 - Equilíbrio Comportamental & 15 & 100 & - & - \\
\hline 12 - Comunicação & 13 & 86,7 & 2 & 13,3 \\
\hline 13 - Integridade Cutâneo-Mucosa & 14 & 93,3 & 1 & 6,7 \\
\hline
\end{tabular}

Através da TABELA 3 pode-se observar que os juízes consideraram existir um nível de complexidade assistencial crescente nos indicadores críticos apresentados exceto nos indicadores Eliminações e Terapêutica, onde se obteve índices respectivamente de $66,7 \%$ e $60 \%$, abaixo do percentual estabelecido de 70\%. Dessa forma, apenas estes dois indicadores críticos não foram considerados como validados devendo ser refeitos e submetidos a novo julgamento.

As sugestões dos juízes na avaliação do nível de complexidade assistencial dos indicadores foram para que se procedesse : 1- alteração da ordem de colocação das gradações existentes; 2- diferenciação entre procedimentos 
terapêuticos e ações de enfermagem; 3- inclusão de outras gradações quanto à suficiência do cuidado.

TABELA 4 - Pareceres dos juízes quanto à clareza do conteúdo dos indicadores críticos do instrumento de classificação - Fase Delphi I . São José do Rio Preto, 1996.

\begin{tabular}{l|cccc}
\hline \multicolumn{1}{|c|}{ INDICADOR CRÍTICO } & \multicolumn{5}{c}{ CLAREZA DO CONTEÚDO } \\
& Sim & \% & Não & \% \\
\hline 1 - Estado Mental e Nível de Consciência & 13 & 86,7 & 2 & 13,3 \\
2 - Oxigenação & 12 & 80 & 3 & 20 \\
3 - Sinais Vitais & 14 & 93,3 & 1 & 6,7 \\
4 - Nutrição e Hidratação & 11 & 73,3 & 4 & 26,7 \\
5 - Motilidade & 14 & 93,3 & 1 & 6,7 \\
6 - Locomoção & 15 & 100 & - & - \\
7 - Cuidado Corporal & 14 & 93,3 & 1 & 6,7 \\
8 - Eliminações & 13 & 86,7 & 2 & 13,3 \\
9 - Terapêutica & 13 & 86,7 & 2 & 13,3 \\
10 - Educação à Saúde & 13 & 86,7 & 2 & 13,3 \\
11 - Equilíbrio Comportamental & 13 & 86,6 & 2 & 13,3 \\
12 - Comunicação & 14 & 93,3 & 1 & 6,7 \\
13 - Integridade Cutâneo- Mucosa & 15 & 100 & - & - \\
\hline
\end{tabular}

Pode-se notar pelos dados da TABELA 4 que a totalidade dos indicadores críticos obteve índices iguais ou superiores a $70 \%$ no que se refere à clareza do conteúdo expresso nos indicadores críticos.

Houve comentários dos juízes quanto à necessidade de haver homogeneização na grafia para as cinco gradações a fim de facilitar o entendimento. 


\subsection{Fase Delphi II}

As apreciações dos juízes, referentes aos 13 indicadores críticos propostos no primeiro instrumento para classificação de pacientes, embasou a construção deste segundo questionário.

A avaliação dos resultados, na $1^{\text {a }}$ fase Delphi, havia revelado consenso dos juízes no que diz respeito à manutenção dos 13 indicadores críticos no instrumento. Dessa forma, este aspecto não foi analisado pelos juízes nesta $2^{\mathrm{a}}$ fase.

Apesar do elevado índice de concordância obtido tornar validado o conteúdo dos indicadores críticos, exceto Eliminações e Terapêutica, a modificação na estrutura destes dois últimos indicadores, conforme sugestões dos juízes, conduziu à alteração dos demais indicadores críticos para que a estrutura geral do instrumento não sofresse ruptura. Assim, repetimos todos os 13 indicadores críticos a fim de que fossem novamente julgados quanto ao conteúdo, existência de nível crescente de complexidade assistencial e clareza.

\subsubsection{Resultados}

O instrumento foi, então, novamente encaminhado aos 15 juízes acompanhado de uma carta contendo explicações sobre os procedimentos solicitados nesta nova fase. Foi estabelecido que a devolução dos questionários se daria no prazo de 10 dias (ANEXO 2).

O instrumento apresentado aos juízes seguiu a seguinte forma de construção : 
1 - Estado Mental e Nível de consciência (habilidade em manter a percepção e as atividades cognitivas)

1- Acordado ; interpretação precisa de ambiente e tempo ; executa, sempre, corretamente, ordens verbalizadas ; preservação da memória .

2- Acordado ; interpretação precisa de ambiente e tempo ; segue instruções corretamente apenas algumas vezes ; dificuldade de memória.

3- Acordado ; interpretação imprecisa de ambiente e tempo em alguns momentos ; dificilmente segue instruções corretamente ; dificuldade aumentada de memória. 4- Acordado ; interpretação imprecisa de ambiente e tempo em todos os momentos; não segue instruções corretamente ; perda de memória.

5 -Desacordado ; ausência de resposta verbal e manutenção de respostas à estímulos dolorosos ou ausência de respostas verbais e motoras.

2 - Oxigenação (aptidão em manter a permeabilidade das vias aéreas e o equilíbrio nas trocas gasosas por si mesmo, com auxílio da equipe de enfermagem e/ou de equipamentos)

1- Não requer oxigenoterapia.

2- Requer uso intermitente ou contínuo de oxigênio sem necessidade de desobstrução de vias aéreas.

3- Requer uso intermitente ou contínuo de oxigênio com necessidade de desobstrução de vias aéreas.

4- Requer uso de oxigênio por traqueostomia ou tubo orotraqueal .

5- Requer ventilação mecânica. 
3 - Sinais Vitais (necessidade de observação e de controle dos parâmetros vitais: temperatura corporal, pulso, padrão respiratório e saturação de oxigênio , pressão arterial média e venosa central).

1- Requer controle de sinais vitais em intervalos de 6 horas

2- Requer controle de sinais vitais em intervalos de 4 horas

3- Requer controle de sinais vitais em intervalos de 2 horas

4- Requer controle de sinais vitais em intervalos menores do que 2 horas

5- Requer controle de sinais vitais em intervalos menores do que 2 horas e/ou controle de pressão arterial média, pressão venosa central ou saturação de oxigênio.

4 - Nutrição e Hidratação (habilidade de ingerir nutrientes e líquidos para atender às necessidades metabólicas, por si mesmo, com auxílio de acompanhantes ou da equipe de enfermagem ou por meio de sondas e catéteres)

1- Auto-suficiente

2- Requer encorajamento e supervisão da enfermagem na nutrição e hidratação orais.

3- Requer orientação de enfermagem ao acompanhante para auxílio na nutrição e hidratação orais ou por sonda nasogástrica ou nasoenteral ou estoma.

4- Requer auxílio da enfermagem na nutrição e hidratação oral e/ou assistência de enfermagem na alimentação por sonda nasogástrica ou nasoenteral ou estoma.

5- Requer assistência efetiva da enfermagem para manipulação de catéteres periféricos ou centrais para nutrição e hidratação. 
5 - Motilidade (capacidade de movimentar os segmentos corporais de forma independente, com auxílio de acompanhante ou da equipe de enfermagem ou pelo uso de artefatos)

1- Auto-suficiente

2- Requer estímulo e supervisão da enfermagem para a movimentação de um ou mais segmentos corporais.

3- Requer orientação de enfermagem ao acompanhante para auxílio na movimentação de um ou mais segmentos corporais.

4- Requer auxílio da enfermagem para a movimentação de um ou mais segmentos corporais

5- Requer assistência efetiva da enfermagem para movimentação de qualquer segmento corporal devido a presença de aparelhos gessados, tração, fixador externo e outros, ou por déficit motor.

6- Locomocão (habilidade para movimentar-se dentro do ambiente físico por si só, com auxílio de acompanhantes ou da equipe de enfermagem ou pelo uso de artefatos)

1- Auto-suficiente

2- Requer encorajamento e supervisão da enfermagem para a deambulação.

3- Requer orientação de enfermagem ao acompanhante para auxílio no uso de artefatos (órteses, próteses, muletas, bengalas, cadeiras de rodas, andadores).

4- Requer o auxílio da enfermagem no uso de artefatos para a deambulação.

5- Requer assistência efetiva de enfermagem para locomoção devido `a restrição no leito. 
7- Cuidado Corporal (capacidade para realizar por si mesmo ou com auxílio de outros, atividades de higiene pessoal e conforto, de vestir-se e arrumar-se)

1- Auto-suficiente

2- Requer supervisão de enfermagem na realização do cuidado corporal e conforto.

3- Requer orientação de enfermagem ao acompanhante para auxílio na higiene oral, higiene íntima, banho de chuveiro e medidas de conforto.

4- Requer auxílio da enfermagem na higiene oral, higiene íntima, banho de chuveiro e medidas de conforto.

5- Requer assistência efetiva da enfermagem para o cuidado corporal e medidas de conforto devido à restrição no leito.

$\boldsymbol{8}$ - Eliminações (habilidade em manter as diversas formas de eliminações sozinho, com auxílio de acompanhante ou da enfermagem ou por drenos e estomas)

1- Auto-suficiente

2- Requer supervisão e controle da enfermagem nas eliminações.

3- Requer orientação de enfermagem ao acompanhante para auxílio no uso de comadre, papagaio, troca de fraldas, absorventes e outros.

4- Requer auxílio da enfermagem no uso de comadre, papagaio, troca de fraldas, absorventes e outros.

5- Requer assistência efetiva de enfermagem para manipulação e controle de catéteres, drenos, dispositivo para incontinência urinária ou estomas. 
9 - Terapêutica (utilização dos diversos agentes terapêuticos medicamentosos prescritos)

1- Requer medicação VO de rotina ou ID, SC ou IM.

2- Requer medicação EV contínua ou através de sonda nasogástrica, nasoenteral ou estoma.

3- Requer medicação EV intermitente com manutenção de catéter.

4- Requer uso de sangue e derivados ou expansores plasmáticos ou agentes antineoplásicos.

5- Requer uso de drogas vasoativas.

10 - Educação à Saúde (habilidade do paciente/família em receber e aceitar orientações sobre hábitos de saúde pessoais e/ou ambientais)

1- Orientações de enfermagem ao paciente/família sobre auto-cuidado com pronta compreensão e aceitação das informações recebidas.

2- Orientações de enfermagem ao paciente/família sobre auto-cuidado com dificuldades de compreensão mas com pronta aceitação das informações recebidas.

3- Orientações de enfermagem ao paciente/família sobre auto-cuidado com pronta compreensão mas certa resistência às informações recebidas.

4- Orientações de enfermagem ao paciente/família sobre auto-cuidado com pronta compreensão mas elevada resistência às informações recebidas.

5- Orientações de enfermagem ao paciente/família sobre auto-cuidado com pronta compreensão mas sem aceitação das informações recebidas. 
11- Comportamento (sentimentos, pensamentos e condutas do paciente com relação à sua doença, gerados em sua interação com o processo de hospitalização, a equipe de saúde e/ou família)

Para preencher o indicador abaixo observe as conceituações :

ANSIEDADE - " vago sentimento de catástrofe iminente, apreensão ou sensação de pavor" (TAYLOR, 1992).

SINTOMAS DE ANSIEDADE - alteração da respiração, tremores, sudorese, taquicardia, náusea, vômito, vertigem, anorexia, diarréia, inquietação, perturbação do sono, medo excessivo ou irracional, sensações de falta de ar ou sufocamento, parestesias, tensão muscular (DSM-IV,1995).

RETRAIMENTO SOCIAL - tendência ocasional para evitar contatos sociais ; funcionamento social diminuído.

IRRITABILIDADE - "Irritação : estado relativamente moderado de cólera, expressando-se sobretudo em formas verbais" ( CABRAL;NICK,1979). Ex: exasperação, exaltação.

RETRAIMENTO SOCIAL AUMENTADO - tendência freqüente para evitar contatos sociais.

APATIA -"aparente insensibilidade a tudo o que provoca habitualmente no indivíduo um sentimento ou uma emoção" (FILLIOUD et al, 1981), indiferença. Ex: não manifestação de amor, ódio, alegria, tristeza, medo, raiva.

PASSIVIDADE - "é uma predisposição para sofrer sem iniciativa nem esforço todas as influências exteriores" (FILLIOUD et al, 1981). Ex: Não reação diante de procedimentos de enfermagem, condutas médicas, hospitalização.

DESESPERANÇA - " estado subjetivo em que o individuo vê escolhas pessoais disponíveis limitadas, ou sem alternativas, e está incapaz de mobilizar energia em seu próprio favor" (NANDA, 1986). Ex: ausência ou diminuição de expectativas, projetos e planos de vida.

IMPOTÊNCIA PSÍQUICA - " percepção de que uma pessoa tem de que o que ela pode fazer não altera, significativamente, um resultado ..." ( NANDA, 1982). Ex: demonstração de incapacidade para desempenhar atividades cotidianas ("não sei", "não vou conseguir", "não posso").

AMBIVALÊNCIA DE SENTIMENTOS - " coexistência de dois impulsos, desejos, atitudes ou emoções opostos dirigidos para a mesma pessoa, o mesmo objeto ou o mesmo objetivo ..." 
(DICIONÁRIO Médico Blakiston, 1982). Ex: afirmação/negação, aceitação/rejeição, amor/ódio, alegria/tristeza.

ISOLAMENTO SOCIAL - "privação de contatos sociais ..." (CABRAL; NICK, 1979).

1- Calmo, tranqüilo; preocupações cotidianas

2- Alguns sintomas de ansiedade (até 3) ou queixas e solicitações contínuas ou retraimento social.

3- Irritabilidade excessiva ou retraimento social aumentado ou apatia ou passividade ou queixas excessivas.

4- Sentimento de desesperança ou impotência psíquica ou ambivalência de sentimentos ou acentuada diminuição do interesse por atividades ou aumento da freqüência de sintomas de ansiedade (mais de 3 sintomas).

5- Comportamento destrutivo dirigido a si mesmo e aos outros ou recusa de cuidados de atenção à saúde ou verbalizações hostis e ameaçadoras ou completo isolamento social.

12 - Comunicação (habilidade em usar ou entender a linguagem verbal e não verbal na interação humana)

1-Comunicativo, expressa idéias com clareza e lógica.

2-Dificuldade em se expressar por diferenças sócio-culturais; verbalização inapropriada.

3- Recusa-se a falar; choroso; comunicação não verbal. 
4- Dificuldade em se comunicar por distúrbios de linguagem (afasia, disfasia, disartria) ou sensibilidade dolorosa ao falar ou por barreira física (traqueostomia, entubação) ou deficiência física ou mental.

5- Inapto para comunicar necessidades .

13 - Integridade Cutâneo-Mucosa ( manutenção da pele e mucosas sem danificação ou destruição)

1- Pele íntegra e sem alteração de cor em todas as áreas do corpo.

2- Presença de alteração da cor da pele (equimose, hiperemia) em uma ou mais áreas do corpo sem solução de continuidade

3- Presença de solução de continuidade em uma ou mais áreas do corpo sem presença de exsudato purulento

4- Presença de solução de continuidade em uma ou mais áreas do corpo com presença de exsudato purulento

5- Presença de solução de continuidade em uma ou mais áreas do corpo com presença de exsudato purulento, exposição de tecido muscular e ósseo ; presença de áreas de necrose

A devolução do $2^{\circ}$ questionário possibilitou o tratamento estatístico dos resultados e a compilação dos pareceres dos juízes com respeito aos indicadores críticos do instrumento.

Mostraremos, a seguir, os resultados obtidos nesta $2^{\mathrm{a}}$ fase. 
TABELA 5 - Pareceres dos juízes quanto à pertinência do conteúdo dos indicadores críticos do instrumento de classificação - Fase Delphi II . São José do Rio Preto, 1996.

\begin{tabular}{l|cccc}
\hline \multirow{2}{*}{ INDICADOR CRÍTICO } & \multicolumn{5}{|c}{ PERTINÊNCIA DO CONTEÚDO } \\
& Sim & \% & Não & \% \\
\hline 1 - Estado Mental e Nível de Consciência & 15 & 100 & - & - \\
2 - Oxigenação & 15 & 100 & - & - \\
3 - Sinais Vitais & 14 & 93,3 & 1 & 6,7 \\
4 - Nutrição e Hidratação & 15 & 100 & - & - \\
5 - Motilidade & 15 & 100 & - & - \\
6 - Locomoção & 15 & 100 & - & - \\
7 - Cuidado Corporal & 15 & 100 & - & - \\
8 - Eliminações & 15 & 100 & - & - \\
9 - Terapêutica & 15 & 100 & - & - \\
10 - Educação à Saúde & 15 & 100 & - & - \\
11 - Comportamento & 15 & 100 & - & - \\
12 - Comunicação & 15 & 100 & - & - \\
13 - Integridade Cutâneo-Mucosa & 15 & 100 & - & - \\
\hline
\end{tabular}

A TABELA 5 revela que houve consenso dos juízes no que se refere à propriedade do conteúdo dos indicadores críticos no instrumento. Foram sugeridas algumas substituições de palavras por terminologias mais apropriadas e alterações na grafia das sentenças. 
TABELA 6 - Pareceres dos juízes quanto à existência de nível crescente de complexidade assistencial nos indicadores críticos do instrumento de classificação - Fase Delphi II . São José do Rio Preto, 1996.

\begin{tabular}{l|cccc}
\hline INDICADOR CRÍTICO & GRADAÇ̃̃O & \multicolumn{3}{c}{ ASSISTENCIAL } \\
& Sim & \% & Não & \% \\
\hline 1-Estado Mental e Nível de Consciência & 14 & 93,3 & 1 & 6,7 \\
2- Oxigenação & 15 & 100 & - & - \\
3 - Sinais Vitais & 14 & 93,3 & - & 6,7 \\
4 - Nutrição e Hidratação & 15 & 100 & - & - \\
5 - Motilidade & 15 & 100 & - & - \\
6 - Locomoção & 15 & 100 & - & - \\
7 - Cuidado Corporal & 14 & 93,3 & 1 & 6,7 \\
8 - Eliminações & 14 & 93,3 & 1 & 6,7 \\
9 - Terapêutica & 14 & 93,3 & 1 & 6,7 \\
10 - Educação à Saúde & 14 & 93,3 & 1 & 6,7 \\
11 - Comportamento & 14 & 93,3 & 1 & 6,7 \\
12 - Comunicação & 14 & 93,3 & 1 & 6,7 \\
13 - Integridade Cutâneo-Mucosa & 14 & 93,3 & 1 & 6,7 \\
\hline
\end{tabular}


TABELA 7 - Pareceres dos juízes quanto à clareza do conteúdo dos indicadores críticos no instrumento de classificação - Fase Delphi II. São José do Rio Preto, 1996.

\begin{tabular}{l|cccc}
\hline \multirow{2}{*}{ INDICADOR CRÍTICO } & \multicolumn{5}{c}{ CLAREZA DO CONTEÚDO } \\
& Sim & \% & Não & \% \\
\hline 1 - Estado Mental e Nível de Consciência & 15 & 100 & - & - \\
2 - Oxigenação & 15 & 100 & - & - \\
3 - Sinais Vitais & 15 & 100 & - & - \\
4 - Nutrição e Hidratação & 14 & 93,3 & 1 & 6,7 \\
5 - Motilidade & 15 & 100 & - & - \\
6 - Locomoção & 14 & 93,3 & 1 & 6,7 \\
7 - Cuidado Corporal & 15 & 100 & - & - \\
8 - Eliminações & 14 & 93,3 & 1 & 6,7 \\
9 - Terapêutica & 14 & 93,3 & 1 & 6,7 \\
10 - Educação à Saúde & 14 & 93,3 & 1 & 6,7 \\
11 - Comportamento & 14 & 93,3 & 1 & 6,7 \\
12 - Comunicação & 15 & 100 & - & - \\
13 - Integridade Cutâneo-Mucosa & 13 & 86,7 & 2 & 13,3 \\
\hline
\end{tabular}

Conforme os resultados apresentados nas TABELA 6 e TABELA 7, constatamos que houve convergência nas respostas dos juízes quanto à existência de nível crescente de complexidade assistencial e clareza nos indicadores críticos do presente instrumento para classificação de pacientes. Não houve comentários dos juízes quanto a alterações nestes aspectos. No entanto, quanto ao indicador crítico Integridade Cutâneo-Mucosa, houve diminuição do percentual de concordância em relação à $1^{\mathrm{a}}$ fase, embora o conteúdo deste indicador tenha se mantido inalterado.

Vale ressaltar que o índice de concordância nas respostas obtidas nesta $2^{\mathrm{a}}$ fase igual ou maior a $70 \%$ proporcionou a validação final do instrumento para 
classificação de pacientes, não se tornando necessário a aplicação de um novo questionário.

\subsection{Proposta Final do Instrumento para Classificação}

\section{de Pacientes}

Após as devidas alterações sugeridas pelos juízes, na fase Delphi II, o instrumento para classificação de pacientes, agora validado, adquiriu a seguinte forma final : 


\section{SISTEMA DE CLASSIFICAÇÃO DE PACIENTES}

NOME

UNID ADE

LEITO

DATA

1 - Estado Mental e Nível de Consciência (habilidade em manter a percepção e as atividades cognitivas)

$\square 1$ - Acordado ; interpretação precisa de ambiente e tempo ; executa, sempre, corretamente, ordens verbalizadas ; preservação da memória .

2- Acordado ; interpretação precisa de ambiente e tempo ; segue instruções corretamente apenas algumas vezes; dificuldade de memória.

3- Acordado ; interpretação imprecisa de ambiente e tempo em alguns momentos ; dificilmente segue instruções corretamente ; dificuldade aumentada de memória.

4- Acordado ; interpretação imprecisa de ambiente e tempo em todos os momentos; não segue instruções corretamente ; perda de memória.

5 - Desacordado ; ausência de resposta verbal e manutenção de respostas à estímulos dolorosos ou ausência de respostas verbais e motoras.

2 - Oxigenação (aptidão em manter a permeabilidade das vias aéreas e o equilíbrio nas trocas gasosas por si mesmo, com auxílio da equipe de enfermagem e/ou de equipamentos)

1- Não requer oxigenoterapia. 
2- Requer uso intermitente ou contínuo de oxigênio sem necessidade de desobstrução de vias aéreas.

3- Requer uso intermitente ou contínuo de oxigênio com necessidade de desobstrução de vias aéreas.

4- Requer uso de oxigênio por traqueostomia ou tubo orotraqueal .

5- Requer ventilação mecânica.

3 - Sinais Vitais (necessidade de observação e de controle dos parâmetros vitais: temperatura corporal, pulso, padrão respiratório, saturação de oxigênio e pressão arterial, arterial média e venosa central)

1- Requer controle de sinais vitais em intervalos de 6 horas

2- Requer controle de sinais vitais em intervalos de 4 horas

3- Requer controle de sinais vitais em intervalos de 2 horas

4- Requer controle de sinais vitais em intervalos menores do que 2 horas

5-Requer controle de sinais vitais em intervalos menores do que 2 horas e controle de pressão arterial média e/ou pressão venosa central e/ou saturação de oxigênio.

4 - Nutrição e Hidratação (habilidade de ingerir nutrientes e líquidos para atender às necessidades metabólicas, por si mesmo, com auxílio de acompanhantes ou da equipe de enfermagem ou por meio de sondas e catéteres)

1- Auto-suficiente

2- Requer encorajamento e supervisão da enfermagem na nutrição e hidratação oral 
3- Requer orientação e supervisão de enfermagem ao acompanhante para auxílio na nutrição e hidratação oral

4- Requer auxílio da enfermagem na nutrição e hidratação oral e/ou assistência de enfermagem na alimentação por sonda nasogástrica ou nasoenteral ou estoma.

5-Requer assistência efetiva da enfermagem para manipulação de catéteres periféricos ou centrais para nutrição e hidratação.

5 - Motilidade (capacidade de movimentar os segmentos corporais de forma independente, com auxílio do acompanhante ou da equipe de enfermagem ou pelo uso de artefatos)

1- Auto-suficiente

2- Requer estímulo e supervisão da enfermagem para a movimentação de um ou mais segmentos corporais.

3- Requer orientação e supervisão de enfermagem ao acompanhante para auxílio na movimentação de um ou mais segmentos corporais.

4- Requer auxílio da enfermagem para a movimentação de um ou mais segmentos corporais

5-Requer assistência efetiva da enfermagem para movimentação de qualquer segmento corporal devido a presença de aparelhos gessados, tração, fixador externo e outros, ou por déficit motor. 
6- Locomocão (habilidade para movimentar-se dentro do ambiente físico por si só, com auxílio do acompanhante ou da equipe de enfermagem ou pelo uso de artefatos) 1- Auto-suficiente

2- Requer encorajamento e supervisão da enfermagem para a deambulação.

3- Requer orientação e supervisão de enfermagem ao acompanhante para auxílio no uso de artefatos (órteses, próteses, muletas, bengalas, cadeiras de rodas, andadores).

4- Requer o auxílio da enfermagem no uso de artefatos para a deambulação

5-Requer assistência efetiva de enfermagem para locomoção devido `a restrição no leito.

7- Cuidado Corporal (capacidade para realizar por si mesmo ou com auxílio de outros, atividades de higiene pessoal e conforto, de vestir-se e arrumar-se)

1- Auto-suficiente

2- Requer supervisão de enfermagem na realização do cuidado corporal e conforto.

3- Requer orientação e supervisão de enfermagem ao acompanhante para auxílio na higiene oral, higiene íntima, banho de chuveiro e medidas de conforto.

4- Requer auxílio da enfermagem na higiene oral, higiene íntima, banho de chuveiro e medidas de conforto.

5-Requer assistência efetiva da enfermagem para o cuidado corporal e medidas de conforto devido à restrição no leito. 
8 - Eliminações (habilidade em manter as diversas formas de eliminações sozinho, com auxílio do acompanhante ou da enfermagem ou por drenos e estomas)

1- Auto-suficiente

2- Requer supervisão e controle pela enfermagem das eliminações.

3- Requer orientação e supervisão de enfermagem ao acompanhante para auxílio no uso de comadre, papagaio, troca de fraldas, absorventes e outros, e controle, pela enfermagem, das eliminações

4- Requer auxílio e controle pela enfermagem no uso de comadre, papagaio, troca de fraldas, absorventes e outros.

5-Requer assistência efetiva de enfermagem para manipulação e controle de catéteres, drenos, dispositivo para incontinência urinária ou estomas.

9 - Terapêutica (utilização dos diversos agentes terapêuticos medicamentosos prescritos)

1- Requer medicação VO de rotina ou ID, SC ou IM.

2- Requer medicação EV contínua e/ou através de sonda nasogástrica, nasoenteral ou estoma.

3-Requer medicação EV intermitente com manutenção de catéter.

4-Requer uso de sangue e derivados ou expansores plasmáticos ou agentes citostáticos.

5-Requer uso de drogas vasoativas ou outras que exigem maiores cuidados na administração. 
10 - Educação à Saúde (habilidade do paciente/família em receber e aceitar orientações sobre auto-cuidado)

1- Orientações de enfermagem ao paciente/família sobre auto-cuidado com pronta compreensão e aceitação das informações recebidas.

2- Orientações de enfermagem ao paciente/família sobre auto-cuidado com dificuldades de compreensão mas com pronta aceitação das informações recebidas.

3- Orientações de enfermagem ao paciente/família sobre auto-cuidado com pronta compreensão mas certa resistência às informações recebidas.

4- Orientações de enfermagem ao paciente/família sobre auto-cuidado com pronta compreensão mas elevada resistência às informações recebidas.

5- Orientações de enfermagem ao paciente/família sobre auto-cuidado com pronta compreensão mas sem aceitação das informações recebidas.

11- Comportamento (sentimentos, pensamentos e condutas do paciente com relação à sua doença, gerados em sua interação com o processo de hospitalização, a equipe de saúde e/ou família)

Para preencher o indicador abaixo observe as conceituações :

ANSIEDADE - "vago sentimento de catástrofe iminente, apreensão ou sensação de pavor" (TAYLOR, 1992).

SINTOMAS DE ANSIEDADE - alteração da respiração, tremores, sudorese, taquicardia, náusea, vômito, vertigem, anorexia, diarréia, inquietação, perturbação do sono, medo excessivo ou irracional, sensações de falta de ar ou sufocamento, parestesias, tensão muscular (DSM-IV,1995). 
RETRAIMENTO SOCIAL - tendência ocasional para evitar contatos sociais ; funcionamento social diminuído.

IRRITABILIDADE - "Irritação : estado relativamente moderado de cólera, expressando-se sobretudo em formas verbais" (CABRAL;NICK,1979). Ex: exasperação, exaltação.

RETRAIMENTO SOCIAL AUMENTADO - tendência freqüente para evitar contatos sociais. APATIA -"aparente insensibilidade a tudo o que provoca habitualmente no indivíduo um sentimento ou uma emoção" (FILLIOUD et al, 1981), indiferença. Ex: não manifestação de amor, ódio, alegria, tristeza, medo, raiva.

PASSIVIDADE - "é uma predisposição para sofrer sem iniciativa nem esforço todas as influências exteriores" (FILLIOUD et al, 1981). Ex: Não reação diante de procedimentos de enfermagem, condutas médicas, hospitalização.

DESESPERANÇA - " estado subjetivo em que o indivíduo vê escolhas pessoais disponíveis limitadas, ou sem alternativas, e está incapaz de mobilizar energia em seu próprio favor" (NANDA, 1986). Ex: ausência ou diminuição de expectativas, projetos e planos de vida.

IMPOTÊNCIA PSÍQUICA - " percepção de que uma pessoa tem de que o que ela pode fazer não altera, significativamente, um resultado ..." ( NANDA, 1982). Ex: demonstração de incapacidade para desempenhar atividades cotidianas ("não sei", "não vou conseguir"," "não posso").

AMBIVALENCIA DE SENTIMENTOS - " coexistência de dois impulsos, desejos, atitudes ou emoções opostos dirigidos para a mesma pessoa, o mesmo objeto ou o mesmo objetivo ..." (DICIONÁRIO Médico Blakiston, 1982). Ex: afirmação/negação, aceitação/rejeição, amor/ódio, alegria/tristeza.

ISOLAMENTO SOCIAL - "privação de contatos sociais ..." (CABRAL; NICK, 1979) .

1- Calmo, tranqüilo; preocupações cotidianas

2- Alguns sintomas de ansiedade (até 3) ou queixas e solicitações contínuas ou retraimento social. 
3- Irritabilidade excessiva ou retraimento social aumentado ou apatia ou passividade ou queixas excessivas.

4- Sentimento de desesperança ou impotência psíquica ou ambivalência de sentimentos ou acentuada diminuição do interesse por atividades ou aumento da freqüência de sintomas de ansiedade (mais de 3 sintomas).

5-Comportamento destrutivo dirigido a si mesmo e aos outros ou recusa de cuidados de atenção à saúde ou verbalizações hostis e ameaçadoras ou completo isolamento social.

12 - Comunicação (habilidade em usar ou entender a linguagem verbal e não verbal na interação humana)

1-Comunicativo, expressa idéias com clareza e lógica.

2- Dificuldade em se expressar por diferenças sócio-culturais; verbalização inapropriada.

3- Recusa-se a falar; choroso; comunicação não verbal.

4- Dificuldade em se comunicar por distúrbios de linguagem (afasia, disfasia, disartria) ou sensibilidade dolorosa ao falar ou por barreira física (traqueostomia, entubação) ou deficiência física ou mental.

5-Inapto para comunicar necessidades .

13 - Integridade Cutâneo-Mucosa ( manutenção da pele e mucosas sem danificação ou destruição) 
1- Pele íntegra e sem alteração de cor em todas as áreas do corpo.

2- Presença de alteração da cor da pele (equimose, hiperemia ou outras) em uma ou mais áreas do corpo sem solução de continuidade

3- Presença de solução de continuidade em uma ou mais áreas do corpo sem presença de exsudato purulento

4- Presença de solução de continuidade em uma ou mais áreas do corpo com presença de exsudato purulento, sem exposição de tecido muscular e/ou ósseo; ausência de áreas de necrose.

5- Presença de solução de continuidade em uma ou mais áreas do corpo com presença de exsudato purulento, exposição de tecido muscular e/ou ósseo ; presença de áreas de necrose

\section{AVALIAÇÃO DO TIPO DE CUIDADO :}

Cuidados Mínimos : 13 a 26 pontos

- cuidados a pacientes estáveis sob o ponto de vista clínico e de enfermagem, mas fisicamente auto-suficientes quanto às necessidades humanas básicas;

Cuidados Intermediários : 27 a 39 pontos 
- cuidados a pacientes estáveis sob o ponto de vista clínico e de enfermagem, com parcial dependência das ações de enfermagem para o atendimento das necessidades humanas básicas;

Cuidados Semi-Intensivos : 40 a 52 pontos

- cuidados a pacientes recuperáveis ou crônicos, estáveis sob o ponto de vista clínico, porém, com total dependência das ações de enfermagem quanto ao atendimento das necessidades humanas básicas.

\section{Cuidados Intensivos : 53 a 65 pontos}

- cuidados a pacientes graves, com risco iminente de vida, sujeitos à instabilidade de sinais vitais, que requeiram assistência de enfermagem permanente e especializada;

Total da pontuação :

Classificação :

Enfermeira : 


\section{CONCLUSÕES}

A construção deste instrumento para classificação de pacientes foi baseada nas necessidades individualizadas de cuidado de enfermagem. Para tanto, utilizamos indicadores críticos de cuidado que não se restringissem apenas a esfera biológica, como ocorre em muito sistemas de classificação, mas que considerassem a dimensão psicossocial do cuidado, tais como : Comunicação, Comportamento e

\section{Educação à Saúde.}

Houve, também, a preocupação em se manter um número maior de gradações (5) do que o usual, nos indicadores, para que a variabilidade no grau de complexidade dos pacientes fosse contemplada.

Assim, o instrumento atua como um norteador das necessidades de cuidado evitando a tendência de se enquadrar o paciente dentro de uma categoria de cuidado não compatível com suas reais necessidades, sub ou superestimando o seu nível de complexidade assistencial.

A inclusão da presença do acompanhante no atendimento ao paciente, como expressa nos indicadores críticos : Nutrição e Hidratação, Motilidade, Locomoção, Cuidado Corporal e Eliminações, é uma variável que deverá ser considerada nas horas de assistência prestadas pela enfermeira.

Embora, em nossa proposta, todos os indicadores do instrumento de classificação tenham sido tratados com uniformidade de importância na determinação do tipo de cuidado, acreditamos que, na prática, isto não ocorra. Pensamos que, por 
exemplo, a presença de reações comportamentais severas em pacientes com certa auto-suficiência para as necessidades biológicas possa determinar, por si só, a dependência do paciente com relação à assistência de enfermagem.

Por isso, sugerimos que estudos sejam realizados a fim de se verificar se há indicadores compulsórios para uma determinada categoria de cuidado.

A validade do conteúdo do instrumento foi analisada por um grupo de 15 juízes. O julgamento feito por estes profissionais de enfermagem demonstrou concordância quanto à manutenção dos 13 indicadores críticos propostos na composição do instrumento. Foi evidenciada a necessidade de algumas reformulações no conteúdo, no sentido de se destacar alguns procedimentos de enfermagem e uso de equipamentos que não haviam sido contemplados, bem como a exclusão de outros considerados não pertinentes.

O indicador Comportamento, na visão de alguns juízes, foi pertinente para compor o instrumento, embora tenha sido considerado como de difícil abordagem devido à falta de preparo do profissional enfermeiro para avaliá-lo.

Em sua grande maioria, os juízes consideraram existir clareza e nível de complexidade assistencial crescente nos indicadores críticos apresentados, sugerindo algumas modificações quanto a colocação das gradações bem como inclusão de outras gradações quanto à suficiência do cuidado.

É oportuno destacar que, quando da construção do presente instrumento para classificação de pacientes, objetivamos que o mesmo tivesse como característica a abrangência, ou seja, a possibilidade de implementação nas diversas unidades de internação e especializadas. Contudo, os pareceres de juízes atuantes na área de Enfermagem Pediátrica e Neonatal inviabilizaram o uso deste instrumento 
junto à clientela infantil devido à inadequação da forma de apresentação de alguns dos indicadores. Os demais juízes, que atuam nas unidades de Clínica Médica, Cirúrgica, Ginecologia e Obstetrícia, não fizeram qualquer comentário quanto a impossibilidade de utilização do instrumento nestas unidades. Dessa forma, sugerimos a implementação deste instrumento apenas para pacientes adultos hospitalizados.

A aplicação da Técnica Delphi, nesta pesquisa, permitiu que profissionais de enfermagem com experiências diversificadas pudessem contribuir para a construção deste instrumento apontando aspectos que consideram de relevância para a assistência de enfermagem.

Ao nosso ver, só se concebe a elaboração de um instrumento para utilização na prática do enfermeiro quando este esteja em consonância com o contexto assistencial vivenciado por este profissional. Assim, a participação deste grupo de enfermeiras, com amplo conhecimento e vivência na área de enfermagem, tornou o instrumento validado, quanto ao conteúdo, às reais necessidades da enfermeira que atua no processo de cuidar.

Além destes pontos, fica evidente a importância da utilização de um sistema para classificação de pacientes, na prática de enfermagem, como forma de subsidiar a melhoria da qualidade assistencial implementada e que se mostre capaz de prever as necessidades de cuidado individualizado do paciente, correlacionando-a com a alocação de recursos humanos e o custeio do cuidado de enfermagem.

De acordo com estudo de KINLEY; CRONENWETT (1987) é suficiente que se aplique o instrumento de classificação uma vez ao dia, preferencialmente no mesmo plantão. 
Como este estudo se ateve à construção de um instrumento para classificação de pacientes e a sua validação efetuou-se apenas quanto ao aspecto de conteúdo, nos propomos a dar continuidade, em pesquisas futuras, no sentido de processar a validação clínica deste instrumento para verificação de sua aplicabilidade na prática assistencial, em diferentes unidades.

Acreditamos que este sistema de classificação de pacientes possibilite o cálculo das horas da assistência de enfermagem subsidiando, desta forma, o dimensionamento do pessoal de enfermagem. 


\section{ANEXO 1 \\ FASE DELPHI I}

São José do Rio Preto, 01 de julho de 1996

Cara colega :

Estamos desenvolvendo uma pesquisa, na condição de mestranda da EEUSP São Paulo, onde pretendemos construir e validar um instrumento para classificação de pacientes que seja capaz de categorizá-los de acordo com a quantidade de cuidado de enfermagem requerido.

Você foi escolhida por sua experiência profissional para emitir seu julgamento sobre o conteúdo deste instrumento respondendo ao questionário em anexo.

Para elaboração deste instrumento, consideramos 13 indicadores : 1-Estado Mental e Nível de Consciência, 2-Oxigenação, 3-Sinais Vitais, 4-Nutrição e Hidratação, 5Motilidade, 6- Locomoção, 7-Cuidado Corporal, 8-Eliminação, 9-Terapêutica, 10-Educação à Saúde, 11- Equilíbrio Comportamental, 12-Comunicação e 13-Integridade CutâneoMucosa.

Cada um destes indicadores possui gradação de 1 a 5 , apontando a intensidade crescente de complexidade assistencial.

As atividades que solicitamos referem-se a :

1 - Leitura dos 13 indicadores apresentados.

2 - Apreciação sobre a adequação de cada indicador.

3 -Comentários sobre os indicadores acerca da manutenção ou exclusão do mesmo no instrumento, bem como a inclusão de outros indicadores, caso julgue necessário.

4 - Apreciação do conteúdo dos indicadores e se, ao seu ver, obedecem a uma complexidade assistencial crescente, bem como se existe clareza nos enunciados. Deixamos um espaço reservado a algum comentário que você julgue pertinente.

Desde já agradecemos sua disponibilidade em compartilhar seu tempo com nossa pesquisa certa de que sua valiosa contribuição em muito ampliará as possibilidades deste estudo. Colocamo-nos a disposição para eventuais esclarecimentos que se façam necessários. 


\section{1- IDENTIFICAÇÃO}

Nome:

Idade:

Escola onde se graduou:-

Ano

Local de trabalho :

Área de atuação:

\section{2 - QUALIFICAÇÃO}

$\square$ Habilitação: Ano

$\square$ Especialização: Ano-

Tem título de especialista ? Sim Não Qual ?

$\square$ Mestrado em Ano

$\square$ Doutorado em Ano

Outros :

3 - TRAJETÓRIA PROFISSIONAL

\begin{tabular}{|l|l|}
\hline UNIDADES & TEMPO DE ATUAÇÃO \\
\hline & \\
\hline & \\
\hline & \\
\hline & \\
\hline & \\
\hline & \\
\hline & \\
\hline & \\
\hline
\end{tabular}




\section{QUESTIONÁRIO}

\section{I - INDICADORES}

1- Estado Mental e Nível de Consciência (habilidade em manter a percepção e as atividades cognitivas)

é pertinente ? SIM ( ) NÃO ( )

comentários

2- Oxigenação (aptidão em manter a permeabilidade das vias aéreas e o equilíbrio nas trocas gasosas por si mesmo, com auxílio da equipe de enfermagem e/ou de equipamentos)

é pertinente ? SIM ( ) NÃO ( )

comentários

3- Sinais vitais (necessidade de observação e de controle dos parâmetros vitais: temperatura corporal, pulsos, padrão respiratório e pressão sanguínea) é pertinente ? SIM ( ) NÃO ( ) comentários 
4- Nutrição e Hidratação (habilidade de ingerir nutrientes e líquidos para atender às necessidades metabólicas, por si mesmo, com auxílio de outros ou por meio de sondas e catéteres)

é pertinente ? SIM ( ) NÃO ( )

comentários

5- Motilidade (capacidade de movimentar os segmentos corporais de forma independente, com auxílio da equipe de enfermagem ou pelo uso de artefatos) é pertinente ? SIM ( ) NÃO ( ) comentários

6- Locomoção (habilidade para movimentar-se dentro do ambiente físico por si só, com auxílio de terceiros ou pelo uso de artefatos)

é pertinente ? SIM ( ) NÃO ( )

comentários

7- Cuidado Corporal (capacidade para realizar por si mesmo ou com auxílio de outros, atividades de higiene pessoal, de vestir-se e arrumar-se)

é pertinente ? SIM ( ) NÃO ( ) 
comentários

8- Eliminações (habilidade em manter eliminações urinária e intestinal sozinho, com auxílio de terceiros ou por drenos e estoma)

é pertinente ? SIM ( ) NÃO ( )

comentários

9-Terapêutica (utilização dos diversos agentes terapêuticos prescritos)

é pertinente ? SIM ( ) NÃO ( )

comentários

10- Educação à Saúde (habilidade do paciente/família para manutenção dos hábitos de saúde pessoais e/ou ambientais)

é pertinente ? SIM ( ) NÃO ( )

comentários 
11- Equilíbrio Comportamental (sentimentos, pensamentos e condutas do paciente com relação à sua doença, gerados em sua interação com a equipe de saúde e/ou família)

é pertinente ? SIM ( ) NÃO ( )

comentários

12- Comunicação (habilidade em usar ou entender a linguagem na interação humana)

é pertinente ? SIM ( ) NÃO ( )

comentários

13- Integridade Cutâneo-Mucosa (capacidade em manter pele e mucosas sem danificação ou destruição)

é pertinente ? SIM ( ) NÃO ( )

comentários 


\section{II- CLASSIFICAÇÃO}

\section{1 - Estado Mental e Nível de consciência}

1- Acordado ; interpretação precisa do ambiente ; executa corretamente ordens verbalizadas ; preservação da memória .

2- Acordado ; interpretação precisa do ambiente ; interpretação errada de informações ; dificuldades de memória

3- Acordado ; interpretação imprecisa do ambiente em alguns momentos ; dificuldade em seguir instruções ; dificuldade aumentada de memória

4- Acordado ; interpretação imprecisa do ambiente em todos os momentos; não segue instruções; perda de memória

5 -Desacordado ; ausência de resposta verbal e manutenção de respostas à estímulos dolorosos ou ausência de respostas verbais e motoras

conteúdo é pertinente ? SIM ( ) NÃO ( )

há nível crescente de complexidade assistencial ? SIM ( ) NÃO ( )

há clareza ? SIM ( ) NÃO ( )

comentários

\section{2 - Oxigenação}

1- Não depende de oxigenoterapia

2- Uso intermitente ou contínuo de oxigênio

3- Necessita aspiração de secreções traqueobrônquicas

4- Traqueostomia ou tubo endotraqueal com ou sem nebulização

5- Ventilação mecânica

conteúdo é pertinente ? SIM ( ) NÃO ( )

há nível crescente de complexidade assistencial ? SIM ( ) NÃO ( ) 
há clareza ? SIM ( ) NÃO ( )

comentários

\section{3 - Sinais Vitais}

1- Controle de sinais vitais de rotina ( 8 horas)

2- Controle de sinais vitais em intervalos de 6 horas

3- Controle de sinais vitais a cada 4 horas

4- Controle de sinais vitais a cada 2 horas

5- Controle de sinais vitais em intervalo menor do que 2 horas

conteúdo é pertinente ? SIM ( ) NÃO ( )

há nível crescente de complexidade assistencial ? SIM ( ) NÃO ( )

há clareza ? SIM ( ) NÃO ( )

comentários

\section{4 - Nutrição e Hidratação}

1- Auto-suficiente e hidratação oral ou dieta zero

2- Por boca, com auxílio; perfusão EV de 24 horas

3- Por boca, com auxílio; precisa encorajamento

4- Através de SNG ou enteral

5- Alimentação parenteral ( simples ou catéter central )

conteúdo é pertinente ? SIM ( ) NÃO ( ) 
há nível crescente de complexidade assistencial ? SIM ( ) NÃO ( )

há clareza ? SIM ( ) NÃO ( )

comentários

\section{5 - Motilidade}

1- Movimenta sozinho todos os segmentos corporais

2- Requer uso de artefatos para movimentação de qualquer segmento corporal

3- Requer auxílio de terceiros para assistência, supervisão ou ensino na movimentação de qualquer segmento corporal ou requer auxílio de terceiros e uso de artefatos para a movimentação de qualquer segmento corporal

4- Incapacidade para movimentar segmentos corporais por presença de aparelhos gessados, tração , fixador externo e outros

5- Incapacidade para movimentar qualquer segmento corporal

conteúdo é pertinente ? SIM ( ) NÃO ( )

há nível crescente de complexidade assistencial ? SIM ( ) NÃO ( )

há clareza ? SIM ( ) NÃO ( )

comentários

\section{6- Locomocão}

1- Ambulante

2- Necessita encorajamento para deambular

3- Necessita auxílio de outros para deambulação 
4- Locomoção através de cadeira de rodas ou outros artefatos

5- Restrito ao leito

conteúdo é pertinente ? SIM ( ) NÃO ( )

há nível crescente de complexidade assistencial ? SIM ( ) NÃO ( )

há clareza ? SIM ( ) NÃO ( )

comentários

\section{7- Cuidado Corporal}

1- Auto-suficiente

2- Necessita auxílio na higiene íntima

3- Necessita auxílio no banho de chuveiro e/ou na realização de higiene oral

4- Banho no chuveiro em cadeira de higiene com auxílio; higiene oral realizada pela enfermagem

5- Banho no leito; higiene oral realizada pela enfermagem

conteúdo é pertinente ? SIM ( ) NÃO ( )

há nível crescente de complexidade assistencial ? SIM ( ) NÃO ( )

há clareza ? SIM ( ) NÃO ( )

comentários

\section{8 - Eliminações}

1- Auto-suficiente 
2- Uso de vaso sanitário com auxílio de enfermagem

3- Uso de comadre com eliminações no leito ou uso de fraldas

4- Irrigação vesical ou urostomia ou colostomia ou ileostomia

5- Evacuação no leito e presença de cateter vesical ou dispositivo para incontinência urinária

conteúdo é pertinente ? SIM ( ) NÃO ( )

há nível crescente de complexidade assistencial ? SIM ( ) NÃO ( )

há clareza ? SIM ( ) NÃO ( )

comentários

\section{9 - Terapêutica}

1- VO de rotina ou IM

2- EV intermitente

3- EV contínua ou através de SNG

4- Uso de sangue e derivados ; expansores plasmáticos

5- Uso de drogas vasoativas

conteúdo é pertinente ? SIM ( ) NÃO ( )

há nível crescente de complexidade assistencial ? SIM ( ) NÃO ( )

há clareza ? SIM ( ) NÃO ( )

comentários 


\section{0 - Educação à Saúde}

1- Orientações ao paciente/família sobre rotinas hospitalares e atividades diárias ou não tem condições para receber orientações

2- Orientações ao paciente/família sobre cuidados perioperatórios ou procedimentos diagnósticos

3- Orientações ao paciente/família sobre auto-cuidado com pronta compreensão

4- Orientações ao paciente/família apreensivos ou resistentes sobre auto-cuidado

5- Orientações ao paciente/família com severas reações emocionais sobre autocuidado

conteúdo é pertinente ? SIM ( ) NÃO ( )

há nível crescente de complexidade assistencial ? SIM ( ) NÃO ( )

há clareza ? SIM ( ) NÃO ( )

comentários

\section{1- Equilíbrio Comportamental}

Para preencher o indicador abaixo observe as conceituações :

ANSIEDADE - " vago sentimento de catástrofe iminente, apreensão ou sensação de pavor" (TAYLOR, 1992).

SINTOMAS DE ANSIEDADE - alteração da respiração, tremores, sudorese, taquicardia, náusea, vômito, vertigem, anorexia, diarréia, inquietação, perturbação do sono, medo excessivo ou irracional, sensações de falta de ar ou sufocamento, parestesias, tensão muscular.( DSM-IV,1995).

RETRAIMENTO SOCIAL - tendência ocasional para evitar contatos sociais ; funcionamento social diminuido.

IRRITABILIDADE - "Irritação : estado relativamente moderado de cólera, expressando-se sobretudo em formas verbais" ( CABRAL;NICK,1979). Ex: exasperação, exaltação

RETRAIMENTO SOCIAL AUMENTADO - tendência frequente para evitar contatos sociais.

APATIA -"aparente insensibilidade a tudo o que provoca habitualmente no indivíduo um sentimento ou uma emoção" (FILLIOUD et al, 1981), indiferença. Ex: não manifestação de amor, ódio, alegria, tristeza, medo, raiva. 
PASSIVIDADE - "é uma predisposição para sofrer sem iniciativa nem esforço todas as influências exteriores" (FILLIOUD et al, 1981). Ex: Não reação diante de procedimentos de enfermagem, condutas médicas, hospitalização.

DESESPERANÇA - " estado subjetivo em que o indivíduo vê escolhas pessoais disponíveis limitadas, ou sem alternativas, e está incapaz de mobilizar energia em seu próprio favor" (NANDA, 1986). Ex: ausência ou diminuição de expectativas, projetos e planos de vida.

IMPOTÊNCIA PSÍQUICA - " percepção de que uma pessoa tem de que o que ela pode fazer não altera, significativamente, um resultado ..." ( NANDA, 1982). Ex: demonstração de incapacidade para desempenhar atividades cotidianas ( "não sei", "não vou conseguir","não posso").

AMBIVALÊNCIA DE SENTIMENTOS - " coexistência de dois impulsos, desejos, atitudes ou emoções opostos dirigidos para a mesma pessoa, o mesmo objeto ou o mesmo objetivo ..." (DICIONÁRIO Médico Blakiston, 1982).Ex: afirmação/negação, aceitação/rejeição, amor/ódio, alegria/tristeza.

ISOLAMENTO SOCIAL - "privação de contatos sociais ..." (CABRAL; NICK, 1979) .

1- Calmo, tranquilo; preocupações cotidianas

2- Alguns sintomas de ansiedade ( até 3 ) ou queixas e solicitações contínuas ou retraimento social

3- Irritabilidade excessiva ou retraimento social aumenta ou apatia ou passividade ou queixas excessivas

4- Sentimento de desesperança ou impotência psíquica ou ambivalência de sentimentos ou acentuada diminuição do interesse por atividades ou aumento da frequência de sintomas de ansiedade ( mais de 3 sintomas )

5- Comportamento destrutivo dirigido a si mesmo e aos outros ou recusa de cuidados de atenção à saúde ou verbalizações hostis e ameaçadoras ou completo isolamento social

conteúdo é pertinente ? SIM ( ) NÃO ( )

há nível crescente de complexidade assistencial ? SIM ( ) NÃO ( )

há clareza ? SIM ( ) NÃO ( )

comentários 


\section{2 - Comunicação}

1-Comunicativo, expressa idéias com clareza e lógica

2- Dificuldade em se expressar por diferenças sócio-culturais; verbalização inapropriada

3- Recusa-se a falar; choroso; comunicação não verbal

4- Dificuldade em se comunicar por distúrbios de linguagem ( afasia, disfasia, disartria) ou sensibilidade dolorosa ao falar ou por barreira física (traqueostomia, entubação )

5- Inapto para comunicar necessidades

conteúdo é pertinente ? SIM ( ) NÃO ( )

há nível crescente de complexidade assistencial ? SIM ( ) NÃO ( )

há clareza ? SIM ( ) NÃO ( )

comentários

\section{3 - Integridade Cutâneo-Mucosa}

1- Pele, em uma ou mais áreas do corpo, sem solução de continuidade e sem alteração de cor

2- Presença de alteração da cor da pele ( equimose, hiperemia ) em uma ou mais áreas do corpo sem solução de continuidade

3- Presença de solução de continuidade em uma ou mais áreas do corpo sem presença de exsudato purulento

4- Presença de solução de continuidade em uma ou mais áreas do corpo com presença de exsudato purulento 
5- Presença de solução de continuidade em uma ou mais áreas do corpo com presença de exsudato purulento, exposição de tecido muscular e ósseo ; presença de áreas de necrose

conteúdo é pertinente ? SIM （ ） NÃO ( )

há nível crescente de complexidade assistencial ? SIM ( ) NÃO ( )

há clareza ? SIM ( ) NÃO ( )

comentários 


\section{ANEXO 2 \\ FASE DELPHI II}

São José do Rio Preto, 31 de julho de 1996

Cara Colega:

Dando continuidade à nossa pesquisa, estamos entregando a você um segundo questionário para a validação final do instrumento de classificação de pacientes.

Em nosso primeiro questionário, solicitamos que cada juiz assinalasse a pertinência ou não dos indicadores no instrumento, bem como, que julgasse o conteúdo, clareza e a existência de nível de complexidade assistencial crescente dos mesmos.

Houve consenso dos juízes no que diz respeito à manutenção dos 13 indicadores propostos. Os índices de concordância mostraram-se superiores a 70\% na avaliação do conteúdo, nível de complexidade crescente e clareza de todos os indicadores exceto nos indicadores Eliminações e Terapêutica. Alguns juízes emitiram pareceres para modificação da estrutura e conteúdo dos demais indicadores. Apesar do elevado índice de concordância obtido tornar validado o conteúdo dos outros 11 indicadores, a modificação na estrutura dos indicadores Eliminações e Terapêutica, conforme sugestões, levou a alteração dos demais indicadores para que a estrutura geral do instrumento não sofresse ruptura.

Dessa forma, repetimos todos os indicadores para que sejam novamente julgados quanto ao conteúdo, nível crescente de complexidade e clareza .

Para esta segunda fase solicitamos :

1-Leitura dos 13 indicadores apresentados

2-Apreciação sobre cada indicador com respeito à pertinência do conteúdo, seguimento de um nível de complexidade crescente e clareza nos enunciados, assinalando SIM ou NÃO para cada um dos tópicos. Você poderá, ainda, acrescentar algum comentário, se julgar necessário. A sua resposta nesta fase é decisiva.

Reiteramos nossos agradecimentos por sua disponibilidade e importante participação em nossa pesquisa a fim de que ela chegasse a termo.

Colocamo-nos à disposição para eventuais esclarecimentos que se façam necessários. 


\section{QUESTIONÁRIO}

1 - Estado Mental e Nível de consciência (habilidade em manter a percepção e as atividades cognitivas)

1- Acordado ; interpretação precisa de ambiente e tempo ; executa, sempre, corretamente, ordens verbalizadas ; preservação da memória .

2- Acordado ; interpretação precisa de ambiente e tempo ; segue instruções corretamente apenas algumas vezes; dificuldade de memória.

3- Acordado ; interpretação imprecisa de ambiente e tempo em alguns momentos ; dificilmente segue instruções corretamente; dificuldade aumentada de memória.

4- Acordado ; interpretação imprecisa de ambiente e tempo em todos os momentos; não segue instruções corretamente ; perda de memória.

5 -Desacordado ; ausência de resposta verbal e manutenção de respostas à estímulos dolorosos ou ausência de respostas verbais e motoras.

conteúdo é pertinente ? SIM ( ) NÃO ( )

há nível crescente de complexidade assistencial ? SIM ( ) NÃO ( )

há clareza ? SIM ( ) NÃO ( )

comentários

2 - Oxigenação (aptidão em manter a permeabilidade das vias aéreas e o equilíbrio nas trocas gasosas por si mesmo, com auxílio da equipe de enfermagem e/ou de equipamentos)

1- Não requer oxigenoterapia.

2- Requer uso intermitente ou contínuo de oxigênio sem necessidade de desobstrução de vias aéreas.

3- Requer uso intermitente ou contínuo de oxigênio com necessidade de desobstrução de vias aéreas. 
4- Requer uso de oxigênio por traqueostomia ou tubo orotraqueal .

5- Requer ventilação mecânica.

conteúdo é pertinente ? SIM ( ) NÃO ( )

há nível crescente de complexidade assistencial ? SIM ( ) NÃO ( )

há clareza ? SIM ( ) NÃO ( )

comentários

3 - Sinais Vitais (necessidade de observação e de controle dos parâmetros vitais: temperatura corporal, pulso, padrão respiratório e saturação de oxigênio, pressão arterial média e venosa central).

1- Requer controle de sinais vitais em intervalos de 6 horas

2- Requer controle de sinais vitais em intervalos de 4 horas

3- Requer controle de sinais vitais em intervalos de 2 horas

4- Requer controle de sinais vitais em intervalos menores do que 2 horas

5- Requer controle de sinais vitais em intervalos menores do que 2 horas e/ou controle de pressão arterial média, pressão venosa central ou saturação de oxigênio.

conteúdo é pertinente ? SIM ( ) NÃO ( )

há nível crescente de complexidade assistencial ? SIM ( ) NÃO ( )

há clareza ? SIM ( ) NÃO ( )

comentários

4 - Nutrição e Hidratação (habilidade de ingerir nutrientes e líquidos para atender às necessidades metabólicas, por si mesmo, com auxílio de acompanhantes ou da equipe de enfermagem ou por meio de sondas e catéteres)

1- Auto-suficiente 
2- Requer encorajamento e supervisão da enfermagem na nutrição e hidratação orais. 3- Requer orientação de enfermagem ao acompanhante para auxílio na nutrição e hidratação orais ou por sonda nasogástrica ou nasoenteral ou estoma.

4- Requer auxílio da enfermagem na nutrição e hidratação oral e/ou assistência de enfermagem na alimentação por sonda nasogástrica ou nasoenteral ou estoma.

5- Requer assistência efetiva da enfermagem para manipulação de catéteres periféricos ou centrais para nutrição e hidratação.

conteúdo é pertinente ? SIM ( ) NÃO ( )

há nível crescente de complexidade assistencial ? SIM ( ) NÃO ( )

há clareza ? SIM ( ) NÃO ( )

comentários

5 - Motilidade (capacidade de movimentar os segmentos corporais de forma independente, com auxílio de acompanhante ou da equipe de enfermagem ou pelo uso de artefatos)

1- Auto-suficiente

2- Requer estímulo e supervisão da enfermagem para a movimentação de um ou mais segmentos corporais

3- Requer orientação de enfermagem ao acompanhante para auxílio na movimentação de um ou mais segmentos corporais.

4- Requer auxílio da enfermagem para a movimentação de um ou mais segmentos corporais

5- Requer assistência efetiva da enfermagem para movimentação de qualquer segmento corporal devido a presença de aparelhos gessados, tração, fixador externo e outros, ou por déficit motor

conteúdo é pertinente ? SIM ( ) NÃO ( )

há nível crescente de complexidade assistencial ? SIM ( ) NÃO ( ) 
há clareza ? SIM ( ) NÃO ( )

comentários

6- Locomoção (habilidade para movimentar-se dentro do ambiente físico por si só, com auxílio de acompanhantes ou da equipe de enfermagem ou pelo uso de artefatos)

1- Auto-suficiente

2- Requer encorajamento e supervisão da enfermagem para a deambulação

3- Requer orientação de enfermagem ao acompanhante para auxílio no uso de artefatos (órteses, próteses, muletas, bengalas, cadeiras de rodas, andadores)

4- Requer o auxílio da enfermagem no uso de artefatos para a deambulação

5- Requer assistência efetiva de enfermagem para locomoção devido `a restrição no leito

conteúdo é pertinente ? SIM ( ) NÃO ( )

há nível crescente de complexidade assistencial ? SIM ( ) NÃO ( )

há clareza ? SIM ( ) NÃO ( )

comentários

7- Cuidado Corporal (capacidade para realizar por si mesmo ou com auxílio de outros, atividades de higiene pessoal e conforto, de vestir-se e arrumar-se)

1- Auto-suficiente

2- Requer supervisão de enfermagem na realização do cuidado corporal e conforto

3- Requer orientação de enfermagem ao acompanhante para auxílio na higiene oral, higiene íntima, banho de chuveiro e medidas de conforto

4- Requer auxílio da enfermagem na higiene oral, higiene íntima, banho de chuveiro e medidas de conforto 
5- Requer assistência efetiva da enfermagem para o cuidado corporal e medidas de conforto devido à restrição no leito

conteúdo é pertinente ? SIM ( ) NÃO ( )

há nível crescente de complexidade assistencial ? SIM ( ) NÃO ( )

há clareza ? SIM ( ) NÃO ( )

comentários

8 - Eliminações (habilidade em manter as diversas formas de eliminações sozinho, com auxílio de acompanhante ou da enfermagem ou por drenos e estomas)

1- Auto-suficiente

2- Requer supervisão e controle da enfermagem nas eliminações.

3- Requer orientação de enfermagem ao acompanhante para auxílio no uso de comadre, papagaio, troca de fraldas, absorventes e outros.

4- Requer auxílio da enfermagem no uso de comadre, papagaio, troca de fraldas, absorventes e outros.

5- Requer assistência efetiva de enfermagem para manipulação e controle de catéteres, drenos, dispositivo para incontinência urinária ou estomas.

conteúdo é pertinente ? SIM ( ) NÃO ( )

há nível crescente de complexidade assistencial ? SIM ( ) NÃO

há clareza ? SIM ( ) NÃO ( )

comentários

9 - Terapêutica (utilização dos diversos agentes terapêuticos medicamentosos prescritos)

1- Requer medicação VO de rotina ou ID, SC ou IM. 
2- Requer medicação EV contínua ou através de sonda nasogástrica, nasoenteral ou estoma.

3- Requer medicação EV intermitente com manutenção de catéter.

4- Requer uso de sangue e derivados ou expansores plasmáticos ou agentes antineoplásicos.

5- Requer uso de drogas vasoativas.

conteúdo é pertinente ? SIM ( ) NÃO ( )

há nível crescente de complexidade assistencial ? SIM ( ) NÃO ( )

há clareza ? SIM ( ) NÃO ( )

comentários

10 - Educação à Saúde (habilidade do paciente/família em receber e aceitar orientações sobre hábitos de saúde pessoais e/ou ambientais)

1- Orientações de enfermagem ao paciente/família sobre auto-cuidado com pronta compreensão e aceitação das informações recebidas.

2- Orientações de enfermagem ao paciente/família sobre auto-cuidado com dificuldades de compreensão mas com pronta aceitação das informações recebidas.

3- Orientações de enfermagem ao paciente/família sobre auto-cuidado com pronta compreensão mas certa resistência às informações recebidas.

4- Orientações de enfermagem ao paciente/família sobre auto-cuidado com pronta compreensão mas elevada resistência às informações recebidas.

5- Orientações de enfermagem ao paciente/família sobre auto-cuidado com pronta compreensão mas sem aceitação das informações recebidas.

conteúdo é pertinente ? SIM ( ) NÃO ( )

há nível crescente de complexidade assistencial ? SIM ( ) NÃO ( )

há clareza ? SIM ( ) NÃO ( ) 
comentários

11- Comportamento (sentimentos, pensamentos e condutas do paciente com relação à sua doença, gerados em sua interação com o processo de hospitalização, a equipe de saúde e/ou família)

Para preencher o indicador abaixo observe as conceituações :

ANSIEDADE - " vago sentimento de catástrofe iminente, apreensão ou sensação de pavor" (TAYLOR, 1992).

SINTOMAS DE ANSIEDADE - alteração da respiração, tremores, sudorese, taquicardia, náusea, vômito, vertigem, anorexia, diarréia, inquietação, perturbação do sono, medo excessivo ou irracional, sensações de falta de ar ou sufocamento, parestesias, tensão muscular (DSM-IV,1995).

RETRAIMENTO SOCIAL - tendência ocasional para evitar contatos sociais ; funcionamento social diminuído.

IRRITABILIDADE - "Irritação : estado relativamente moderado de cólera, expressando-se sobretudo em formas verbais" ( CABRAL;NICK,1979). Ex: exasperação, exaltação.

RETRAIMENTO SOCIAL AUMENTADO - tendência freqüente para evitar contatos sociais.

APATIA -"aparente insensibilidade a tudo o que provoca habitualmente no indivíduo um sentimento ou uma emoção" (FILLIOUD et al, 1981), indiferença. Ex: não manifestação de amor, ódio, alegria, tristeza, medo, raiva.

PASSIVIDADE - "é uma predisposição para sofrer sem iniciativa nem esforço todas as influências exteriores" (FILLIOUD et al, 1981). Ex: Não reação diante de procedimentos de enfermagem, condutas médicas, hospitalização.

DESESPERANÇA - " estado subjetivo em que o indivíduo vê escolhas pessoais disponíveis limitadas, ou sem alternativas, e está incapaz de mobilizar energia em seu próprio favor" (NANDA, 1986). Ex: ausência ou diminuição de expectativas, projetos e planos de vida.

IMPOTÊNCIA PSÍQUICA - " percepção de que uma pessoa tem de que o que ela pode fazer não altera, significativamente, um resultado ..." ( NANDA, 1982). Ex: demonstração de incapacidade para desempenhar atividades cotidianas ( "não sei", "não vou conseguir", "não posso").

AMBIVALÊECIA DE SENTIMENTOS - " coexistência de dois impulsos, desejos, atitudes ou emoções opostos dirigidos para a mesma pessoa, o mesmo objeto ou o mesmo objetivo ..." (DICIONÁRIO Médico Blakiston, 1982). Ex: afirmação/negação, aceitação/rejeição, amor/ódio, alegria/tristeza.

ISOLAMENTO SOCIAL - "privação de contatos sociais ..." (CABRAL; NICK, 1979).

1- Calmo, tranqüilo; preocupações cotidianas 
2- Alguns sintomas de ansiedade (até 3) ou queixas e solicitações contínuas ou retraimento social.

3- Irritabilidade excessiva ou retraimento social aumentado ou apatia ou passividade ou queixas excessivas.

4- Sentimento de desesperança ou impotência psíquica ou ambivalência de sentimentos ou acentuada diminuição do interesse por atividades ou aumento da frequiência de sintomas de ansiedade (mais de 3 sintomas).

5- Comportamento destrutivo dirigido a si mesmo e aos outros ou recusa de cuidados de atenção à saúde ou verbalizações hostis e ameaçadoras ou completo isolamento social.

conteúdo é pertinente ? SIM ( ) NÃO ( )

há nível crescente de complexidade assistencial ? SIM ( ) NÃO ( )

há clareza ? SIM ( ) NÃO ( )

comentários

12 - Comunicação (habilidade em usar ou entender a linguagem verbal e não verbal na interação humana)

1-Comunicativo, expressa idéias com clareza e lógica

2- Dificuldade em se expressar por diferenças sócio-culturais; verbalização inapropriada

3- Recusa-se a falar; choroso; comunicação não verbal

4- Dificuldade em se comunicar por distúrbios de linguagem (afasia, disfasia, disartria) ou sensibilidade dolorosa ao falar ou por barreira física (traqueostomia, entubação) ou deficiência física ou mental

5- Inapto para comunicar necessidades

conteúdo é pertinente ? SIM ( ) NÃO ( )

há nível crescente de complexidade assistencial ? SIM ( ) NÃO ( )

há clareza ? SIM ( ) NÃO ( ) 
comentários

13 - Integridade Cutâneo-Mucosa ( manutenção da pele e mucosas sem danificação ou destruição)

1- Pele íntegra e sem alteração de cor em todas as áreas do corpo.

2- Presença de alteração da cor da pele (equimose, hiperemia) em uma ou mais áreas do corpo sem solução de continuidade

3- Presença de solução de continuidade em uma ou mais áreas do corpo sem presença de exsudato purulento

4- Presença de solução de continuidade em uma ou mais áreas do corpo com presença de exsudato purulento

5- Presença de solução de continuidade em uma ou mais áreas do corpo com presença de exsudato purulento, exposição de tecido muscular e ósseo ; presença de áreas de necrose

conteúdo é pertinente ? SIM ( ) NÃO ( )

há nível crescente de complexidade assistencial ? SIM ( ) NÃO ( )

há clareza ? SIM ( ) NÃO ( )

comentários 


\section{REFERÊNCIAS BIBLIOGRÁFICAS}

01-AlCALÁ, M.U. et al. Cálculo de pessoal : estudo preliminar para o estabelecimento de quadro de pessoal de enfermagem na superintendência médico hospitalar de urgência. São Paulo, Secretaria de Higiene e Saúde, 1982.

02-ALVES, S.M. et al. Enfermagem : contribuição para um cálculo de recursos humanos na área . Rio de Janeiro . Coordenadoria de Comunicação Social do INAMPS, 1988 .

03-ALWARD, R.R. Patient classification systems: the ideal vs. reality. J. Nurs. Adm., v.13, n.2, p. 14-9, 1983.

04-ARNDT, C. ; HUCKBAY, L.M.D. Administração em Enfermagem. 2 ed., Rio de Janeiro, Interamericana, 1983 . cap 10, p. 189 - 215: Alocação de recursos humanos e financeiros.

05-AYDELOTTE, M. Staffing for quality care. J. Nurs. Adm.,v.3, n.2, p.33-6, 1973.

06-BARHAM, V.Z.; SCHNEIDER, W. Matrix : a unique patient classification system . J. Nurs. Adm., v.10, n.12, p. 25-31, 1980.

07-BENKO, M.A. et al . Caracterização do paciente não internado para subsidiar o dimensionamento de pessoal de enfermagem. Apresentado ao $46^{\circ}$ Congresso Brasileiro de Enfermagem. Curitiba, Paraná, 1991.

08-CABRAL, A ; NICK, E. Dicionário Técnico de Psicologia. 2 ed. São Paulo, Cultrix, 1979. 
09-CAMPEDELLI, M. C. et al . Cálculo de pessoal de enfermagem : competência da enfermeira. Rev. Esc. Enf. USP, v. 21, n. 1, p.3-15, 1987.

10-CAR, M. R. Problemas de enfermagem na esfera física em pacientes hospitalizados: caracterização por unidades de internação, cuidado semiintensivo e tratamento intensivo. São Paulo, 1986. 108p. Dissertação (Mestrado) - Escola de Enfermagem, Universidade de São Paulo.

11-CASSEM, N.H. Massachusetts General Hospital handbook of generak hospital psychiatry. 3 ed. , Mosby, 1991. cap. 12, p.237-67 : Depression

12-CHAGNON, M. et al . A patient classification system by level of nursing care requirements. Nurs. Res., v.27, n.2, p. 107-12, 1978.

13-CONSELHO FEDERAL DE ENFERMAGEM. Resolução 189 . Rio de Janeiro . 1996.

14-CONNOR, R. J. et al . Effetive use of nursing resources : a research report. Hospitals • v.35, p. 30-9, 1961 .

15-DANIEL, L.F. Atitudes interpessoais em enfermagem . São Paulo . EPU, 1983. cap. 5, p. 65- 89 : A comunicabilidade na enfermagem.

16-DE GROOT, H.A. Patient classification system evaluation . Part 1 : essencial systems elements. J. Nurs. Adm., v.19, n.6, p. 30-5, 1989a.

17-DE GROOT, H.A. Patient classification system evaluation. Part 2: system selection implementation . J. Nurs. Adm. , v.19, n.6, p. 30 - 5, 1989 b.

18-DICIONÁRIO Médico Blakinston. 2 ed. São Paulo, Andrei, 1982.

19-DIJKERS, M. ; PARADISE, T. PCS : one system for both staffing and costing . Nurs. Manag., v.17, n.1, 25 - 34, 1986. 
20-DSM-IV . Manual diagnóstico e estatístico de transtornos mentais. 4 ed. Porto Alegre, Artes Médicas, 1995.

21-FARIAS, J. N. de et al. Diagnóstico de enfermagem : uma abordagem conceitual e prática. João Pessoa, Santa Marta, 1990 .

22-FARO, A C.M. Do diagnóstico à conduta de enfermagem: a trajetória do cuidar na reabilitação do lesado medular. São Paulo, 1995. 208 p. Tese (Doutorado) - Escola de Enfermagem, Universidade de São Paulo.

23-FEHRING, R. J. Methods to validate nursing diagnoses. Heart Lung, v.16, n.6, p.625-29, 1987.

24-FILlIOUD, A et al. Dicionário de Psicologia do adolescente. São Paulo, Verbo, 1981.

25-FUGULIN, M. F. T. et al . Implantação do sistema de classificação de pacientes na unidade de Clínica Médica do Hospital Universitário de S. Paulo . Rev. Med. $\boldsymbol{H U}$ - USP, v.4, n.1/2, p. 63-8, 1994 .

26-GAIDZINSKI, R. R . O dimensionamento do pessoal de enfermagem segundo a percepção de enfermeiras que vivenciam esta prática. São Paulo, 1994. 259p. Tese (Doutorado)- Escola de Enfermagem, Universidade de São Paulo.

27-GIOVANNETTI, P . Understanding patient classification systems. J. Nurs. Adm., v.9, n.2, p. 4 - 9, 1979 .

28-GIOVANNETTI, P.; MAYER, G.G. Building confidence in Patient Classification

Systems. Nurs. Manag. v.15, n.8, p.31- 4, 1984.

29-GIOVANNETTI, P. ; JOHNSON, J.M. A new generation patient classification system J. Nurs. Adm. , v.20 , n.5 , p. 33 - 40 , 1990 
30-GRANT, J.S.; KINNEY, M.R . Using the Delphi tecnique to examine the content validity of nursing diagnosis . Nurs. Diagn., v.3, n.1, p.12-22, 1992.

31-HAAS, S.A. Patient classification systems : a self-fullfilling prophecy . Nurs. Manag., v.19, n.5, p. $56-62,1988$.

32-HORTA, W.A. Processo de Enfermagem . São Paulo, EPU, 1979.

33-HUCKBAY, L.M. Patient classification system : a basis for staffing. New York, National League for Nursing, 1981.

34-JACKSON, B.S. ; RESNICK, J. Comparing classification systems . Nurs. Manag., v.13, n.11, p. $13-9,1982$.

35-KINLEY, J.; CRONENWETT, L.R. Multiple shift patient classification : is it necessary ? J. Nurs. Adm. , v.17, n.2 , p. 22 - 5, 1987.

36-KOIZUME, M.S. Método de avaliação do nível de consciência e interpretação. Acta Paul. Enf., v.3, n.1 , p. 17 - 24 , 1990.

37-KOIZUME, M.S. et al. O Mini - exame do estado mental (MEM) como identificador da disfunção cognitiva após TCE grave . Rev. Esc. Enf. USP, v.28, n.3, p. $281-92$, dez., 1994.

38-LIMA, M.L.A. Dimensionamento de pessoal de enfermagem em unidades de clínica médica : estudo exploratório . Rev. Gaúcha Enf. , v.6 , n.1 , p. 125$42,1985$.

39-MATOS, A.J. de Repensando o custeio do serviço de enfermagem. In: O papel da enfermagem no gerenciamento dos custos hospitalares. São Paulo, Planisa, 1995.

40-NEVES, E.P. Reflexões acerca dos conceitos auto-cuidado e competência/ poder para o auto-cuidado. Rev. Esc. Enf. USP, v.21 , n.3 , p. 235 - 241, 1987. 
41-NOVAES, H. de M. Padrões e indicadores de qualidade para hospitais. Brasil. Washington . OPAS, 1994 .

42-OLIVEIRA, C.; ROMÁN, A.V. de . Perfil de paciente recurso para classificação assistencial. Rev. Paul. Hosp. , v.24, n.2 , p. 52-8, 1976.

43-PHILLIPS, C.Y. et al . Nursing intensity going beyond patient classification. $\boldsymbol{J}$. Nurs. Adm., v.22, n.4 , p. 46 - 52,1992 .

44-PIÉRON, H. Dicionário de Psicologia. 7 ed. Rio de Janeiro, Globo, 1987.

45-RAMOS, M.L.T. et al . Sistema de classificação de pacientes por grau de dependência do cuidado de enfermagem : ENFSCORE. In : ENFTEC, 5.,São Paulo, 1994. Anais . São Paulo, 1994. p. 128 - 41 .

46-REINERT, P. ; GRANT, D.R. A classification system to meet today's needs. J. Nurs. Adm., v.11, n.1, p. $21-5,1981$.

47-REIS, I.B. et al . Cuidado progressivo ao paciente : implantação e sistematização. Mimeografado .

48-RIBEIRO, C.M. Sistema de classificação de pacientes como subsídio para provimento de pessoal de enfermagem. São Paulo, 1972.98 p. Tese (Doutorado) - Escola de Enfermagem, Universidade de São Paulo .

49-RODRIGUES FILHO, J . Sistema de classificação de pacientes - Parte 1: dimensionamento de pessoal de enfermagem., Rev. Esc. Enf.. USP, v.26, n.3, p. $395-404,1992$.

50-ROMERO, E. A et al. Proposta de um instrumento para a classificação dos cuidados de enfermagem quanto ao grau de dependência. In : ENFTEC, 5., São Paulo, 1994. Anais . São Paulo, 1994. p. 482 - 5 . 
51-ROSEMBAUM, J.F.; POLLACK, M.H. Anxiety . In : CASSEM, N.H. Massachussetts General Hospital Psychiatry . 3 ed. Mosby, 1991. p. 159 190 .

52-SANTOS, S.R. dos . Cálculo de pessoal de enfermagem : estudo de dois métodos. Rev. Esc. Enf. USP, v.26, n.2, p.137- 54, 1992.

53-SPÍNOLA, A.W. de P. Delfos : proposta tenológica alternativa. São Paulo, Faculdade de Saúde Pública da USP, 1984 .

54-TAYLOR, C.M. Fundamentos de Enfermagem Psiquiátrica. 13 ed. Porto Alegre, Artes Médicas, 1992. cap. 12, p. 146-158 : Ansiedade uma resposta ao estresse.

55-VAN SLYCK, A A systems approach to the management of nursing services Part II : patient classification systems . Nurs. Manag., v.22, n.4 , p.23 - 5 , 1991.

56-VAUGHAN, R.G. ; McLEOD, V. Nurse staffing studies : no need to reinvent the wheel. J. Nurs. Adm., v.10, n.3 , p.9-15, 1980 .

57-WHITNEY, J.D. ; KILLIEN , M.G. Establishing predictive validity of a patient classification system. Nurs. Manag. , v.18, n.5 , p. 80 - 6, 1987 .

58-WILLIAMS, M.A. When you don't develop your own : validation methods for patient classification systems . Nurs. Manag. , v.19, n.3, p. 91 - 6, 1988 .

59-WILLIAMS, G.H. ; ANDERSON, J.J. Developing a labor and delivery patient classification systems . Nurs. manag., v.23, n. 10 , p. $74-80,1992$.

60-WILLIAMS, P.L. ; WEBB, C. The Delphi tecnique : a methodological discussion. J. Adv. Nurs. , v.19, n.1, p.180-6, 1994 . 
61-WOLF, H. ; YOUNG, J.P. Staffing the nursing unit : part I . controlled variable staffing. Nurs. Res. , v.14 , n.3 , p.236 - 43, 1965 .

62-WRONA-SEXTON, S . Patient classification systems : another perspective . Nurs. Manag., v.23, n.12, p.38-9, 1992 .

63-ZAGO, M.M.F. Considerações sobre o ensino do paciente cirúrgico. Rev. Esc. Enf. USP, v.27, n.1, p.67 - 71, 1993 . 